\title{
Nanocrystallisation in oxyfluoride systems: mechanisms of crystallisation and photonic properties
}

\author{
A. de Pablos-Martín, A. Durán and M. J. Pascual*
}

Rare earth (RE) doped oxyfluoride glass ceramics possess interesting optical properties with applications in telecommunications and optoelectronics, such as solid state lasers, optical amplifiers, etc. These materials combine the transparency and mechanical and chemical resistance of aluminosilicate glasses with the low phonon energy and facile incorporation of RE ions in the fluoride crystals. The incorporation of RE ions in the crystalline phases enhances the laser emission intensity, a major property of these materials. Transparency is achieved when crystal size is in the nanometric scale, usually below $40 \mathrm{~nm}$, which avoids light scattering. A strict control of the nucleation and crystal growth processes is therefore necessary which requires a deep knowledge of the crystallisation mechanisms. The great activity and publications in this field in the last decades merit a review providing a comparative study of the different nanoglass ceramic systems, their structural and optical characterisation and their main properties and applications. This is the objective of this review paper which includes 232 references. A general discussion on glass nucleation and crystallisation theories and more relevant crystallisation parameters and characterisation techniques are put forward in the first section of the review, focused on nanocrystallisation processes in oxyfluoride systems. In the second section, the principal RE doped glass ceramics are presented. After a general introduction about the luminescence processes, including up- and down-conversion, the behaviour of RE elements in glasses and crystals are discussed. Glass ceramic compositions have been divided as follows: glass ceramics with a glass composition following Wang and Ohwaki's oxyfluoride glass 1 ceramic, ${ }^{1}$ and glass ceramics with different matrix compositions, arranged by crystalline phases. Relevant properties, mainly optical and laser, are described in each system along with the most relevant applications of these materials.

Keywords: Nanocrystallisation, Glass ceramics, Rare earth ions, Luminescence, Up-conversion, Down-conversion

\section{Nanocrystallisation in glasses: crystallisation mechanisms}

Nanotechnology and nanomaterials are considered as key technologies for the twenty-first century. Among these materials, nanoglass ceramics are expected to play a major role, since they offer an improvement of certain properties which have been discovered only recently.

In 1933, Tammann ${ }^{2}$ established the bases of crystallisation in glasses, with two main stages: nucleation and crystal growth. Both processes depend on the temperature and on the matrix and crystalline nuclei composition.

Instituto de Cerámica y Vidrio (CSIC), C/Kelsen 5, Campus de Cantoblanco, 28049 Madrid, Spain

*Corresponding author, email mpascual@icv.csic.es
The main theoretical studies concerning nucleation and crystallisation of glasses were developed in the sixties by Jackson, ${ }^{3}$ Thakur et al., ${ }^{4}$ Turnbull and Cohen, ${ }^{5}$ Uhlmann and Chalmers ${ }^{6}$ and Hammel. ${ }^{7}$ An induction time previous to the nucleation process was suggested, ${ }^{8}$ in order to complete the classical nucleation and crystallisation theories.

The variation of the Gibbs energy for nucleation is explained by two different factors: a negative one, corresponding to the crystallisation energy, and a positive factor, which includes the energy barrier necessary for the formation of a new surface. This leads to the definition of a critical radius. Above this radius, the first factor is predominant, the nuclei are stable and crystal growth is possible. Taking into account the temperature dependence of the thermodynamic driving force, the critical radius decreases with decreasing temperature. Therefore, the nucleation rate usually

(C) 2011 Institute of Materials, Minerals and Mining and ASM International Published by Maney for the Institute and ASM International DOI 10.1179/1743280411Y.0000000004 
exhibits a maximum slightly above the glass transformation temperature $T_{\mathrm{g}}$.

Controlled crystallisation of glasses makes the formation of glass ceramics possible; the process is described in several reviews, the most relevant attributable to Hinz, ${ }^{9}$ Lillie, ${ }^{10}$ Robredo, ${ }^{11}$ Tashiro ${ }^{12}$ and McMillan. ${ }^{13}$

Glass ceramics can be synthesised by several methods:

(i) conventional melting and thermal treatment methods. The crystallisation is controlled through the following steps: (1) cooling up to a stabilisation temperature, where nucleation takes place; (2) heating up to the crystallisation temperature, where crystal growth occurs; and (3) cooling to room temperature. Some parameters must be controlled to carry out this process: ${ }^{14-23}$ temperature range where the nucleation takes place; temperature for maximum nucleation rate; nucleation and crystallisation rate; activation energy; type of crystallisation, that is, superficial or volumetric; the crystalline fraction and dimensionality of the crystal growth. Nucleation can also take place assisted by nucleanting agents. Addition of such nucleants was introduced by Stookey ${ }^{24,25}$ and industrially developed by Corning Glass Works. Phase separation in the parent glasses has a great influence in the subsequent crystallisation, ${ }^{26}$ and is directly dependent on undercooling. A phase enriched in network modifiers reduces the diffusion enthalpy and nucleation is facilitated ${ }^{27}$

(ii) sol-gel. A chemical solution (sol) is thermally treated and aged to produce the fine particles in a network (gel). Glass ceramics are obtained on heat treatment of the gel. Moreover, the precursor sol can be deposited on a substrate to form a film, cast into a container with the desired shape, to obtain glasses, fibres and membranes, or used to synthesise powders (microspheres and nanospheres). The main advantages versus the melting method are lower working temperature and higher homogeneity of the glasses. For glass ceramics obtained by this method, three main applications can be highlighted from the literature: (1) dielectric glass ceramics. Li et al. ${ }^{28}$ developed $\mathrm{BPO}_{4}$ and $\mathrm{Si}_{3}\left(\mathrm{PO}_{4}\right)_{4}$ glass ceramics, for high frequency multilayer inductors; (2) bioactive glass ceramics. Worth mentioning are the works of Cai et al. on development of phosphate glass ceramics, ${ }^{29}$ and Chen et al. who obtained $\mathrm{Na}_{2} \mathrm{Ca}_{2} \mathrm{Si}_{3} \mathrm{O}_{9}$ and extensive formation of amorphous bone-like apatite, ${ }^{30}$ and (3) photonics, based on rare earth (RE) doped materials, ${ }^{31,32}$ where the nanosize of the precipitated crystals is crucial on order to avoid light scattering and increase laser emission.

Despite the great technological potential of nanocrystalline glass ceramics, the fundamentals of the crystallisation mechanisms are not fully understood. Theories of crystallisation are usually restricted to isochemical systems in which the crystalline phase has the same chemical composition as the glass matrix. However, the challenge of obtaining large volume concentrations of crystals with sizes in the $5-50 \mathrm{~nm}$ range and narrow size distribution can only be achieved in multicomponent systems and by controlling the change in the chemical composition of the glass matrix and the interphase formed during nucleation and crystal growth.

Since the nineties, crystallisation of nanosized crystals has been analysed mainly by two different methods:

(i) crystallisation studies through crystallochemistry and thermodynamic procedures; important work was performed by Stoch $^{33}$ and Sroda et al. ${ }^{34}$ who analysed the crystallisation of different species by DTA and considered the ionicity of the bonds involved

(ii) in order to complement the classical nucleation and crystallisation theories, a second trend takes into account the change of the composition during the crystallisation process, studying the interphase created in highly viscous liquids such as glass melts near the glass transition temperature. Two cases can be distinguished: (1) the viscosity of the liquid at the interphase is smaller than that of the bulk; this leads to an increase in the crystal growth rate due to enhanced diffusion. On the contrary, if (ii) the viscosity increases, the interphase will act as a diffusional barrier and will notably decelerate the crystal growth velocity. Relevant authors who have studied these phenomena are Rüssel, Avramov, Keding, Petrini Fogaca de Almeida, Bocker and Hill et al. ${ }^{35-39}$ Rüssel $^{40}$ suggested a mechanism for the crystallisation of $\mathrm{CaF}_{2}$ in aluminosilicate glasses, in which the interphase is enriched in glass formers, increasing the viscosity near the crystals. Thus, a diffusional barrier around each crystal is formed, which hinders further crystal growth. This mechanism opened up a new route in the preparation of nanoglass ceramics, since the nanometric size of the crystals can be controlled via the formation of this viscous barrier.

Superficial stresses developed around crystals, the structure of the melt during cooling and the percolation theories are taken into account for the first time in these works. An interesting explanation is that nucleation takes place into a floppy region if the critical nucleus radius is smaller than this region ${ }^{51}$ and, specially if the average number of covalent bonds per network former unit $\langle n\rangle$ is below $2 \cdot 4 .^{41}$ In this case, a monomodal crystal size distribution is obtained. If $2 \cdot 4\langle n\rangle 3 \cdot 17$, the network is rigid and nucleation first occurs in the small residual floppy regions and thereafter in the rigid part of the network, resulting in a bimodal crystal size distribution. Avramov et al. ${ }^{42}$ and Tsakiris et al. ${ }^{43}$ performed Monte Carlo simulations to study the diffusion process. They assumed a particle moving on a two-dimensional square disordered lattice, containing network formers connected by bonds. Two parameters are decisive for the diffusion analysis: the bond removal probability $f$ and the upper limit of a number of network formers bonds $m$. For each value of $m$, a critical value of $f, f_{\mathrm{c}}$ exists. Below this value, the diffusion of the particle is inhibited by the large number of network former bonds, and above it the particle moves more easily through the lattice. Diffusion takes place when the first neighbouring atoms have a number of bonds which is less than the $m$ value; in other words, they are in a floppy state.

The abovementioned authors have greatly influenced more detailed approaches merging nucleation theory 
and percolation theory. Quite recently, in collaboration with Rüssel, ${ }^{44}$ a model describing the crystal growth was developed taking into account the stress energy developed in the vicinity of the growing crystal. The crystallisation starts rapidly in a floppy region; when this region is totally crystallised, further crystallisation propagates inside the rigid region, giving rise to stress development in the periphery of the crystal, which slows the growth rate. As the stress relaxation is too slow in the rigid region, stress energy can be accumulated.

The simulation parameters $f, f_{\mathrm{c}}, m$ and stress relaxation time $\tau$ give an idea of the range of glass compositions which can develop nanocrystals, avoiding those compositions which exhibit stress free matrix, in which crystals are not able to remain nanometric.

\section{Characterisation techniques}

Various techniques are used for the complete study of glass ceramics.

Dilatometry allows the determination of the glass transition temperature $T_{\mathrm{g}}$, softening point $T_{\mathrm{S}}$ and lineal expansion coefficient $\alpha$, and evaluation of their changes with crystalline fraction.

X-ray diffraction (XRD) permits identification of the crystalline phase and crystalline structure following its evolution with time and temperature of heat treatment, and to calculate the crystalline fraction and crystal sizes.

Differential scanning calorimetry (DSC) ${ }^{45}$ gives information about the activation energy of the global crystallisation process and is useful to calculate the Avrami coefficient and the dimensionality of crystal growth, thereby helping to establish the crystallisation mechanism. Donald ${ }^{46}$ summarises the different crystallisation mechanisms from the values of Avrami parameter, $n$ and $m$, which represent the dimensionality of crystal growth from which bulk crystallisation and surface crystallisation may be discerned. The methods outlined in this paper are nowadays a starting point for elucidating the crystallisation mechanism from DTA/ DSC results. ${ }^{47}$

Different electron microscopies, such as transmission electron microscopy (TEM) and in high resolution mode, scanning electron microscopy, energy filtered transmission electron microscopy and electron energy loss spectroscopy, allow the estimation of the mean crystal size, identification of phase separation ${ }^{26}$ and the recording of compositional elemental mappings.

Nuclear magnetic resonance (NMR) spectroscopy is used to study the first coordination sphere of the glass components. ${ }^{48}$ For instance, the partial substitution of fluoride ions by oxygen in aluminosilicate glasses and its structural role in oxyfluoride glasses can be studied with this technique, due to the high sensitivity of ${ }^{19} \mathrm{~F}$ to its neighbouring atoms and coordination number. ${ }^{49}$

Other techniques used include Fourier transformation infrared spectroscopy, neutron diffraction, Raman spectroscopy and atomic force microscopy.

In terms of the characterisation of optically active materials, a main aspect to study is the distribution of dopant ions between glassy and crystalline phases, since this is decisive in clarifying the emission mechanism and the efficiency dependence on the crystal size and crystalline fraction. Raman, ${ }^{50} \mathrm{NMR},{ }^{51}$ electron paramagnetic resonance ${ }^{52,53}$ and Mössbauer spectroscopies ${ }^{54}$ are useful for establishing a relationship between structure and properties of these materials; together with absorption and linear emission spectroscopies, the environment of RE elements can be analysed. The change of the lattice parameters when the RE ion is incorporated into the crystal structure can be measured by refined XRD patterns.

Optical measurements at low temperature are useful to minimise the effect of phonons produced by lattice vibrations. Absorbance or transmittance measurements permit the identification of the RE electronic levels. Comparing the spectra of glass and glass ceramics, it is possible to detect changes in the RE environment. From absorption spectra, excitation wavelengths are selected to obtain linear emission spectra, which are useful not only for acquiring the complete energy level diagram of the RE ion in the studied matrix, but also to identify changes or displacements in the bands or even the appearance of new bands. Emission spectroscopy allows the calculation of the lifetime of a certain excited level from the luminescence curves. An effective decay constant $\tau_{\text {eff }}$ can be described through equation (1) as

$$
\tau^{\mathrm{eff}}=\frac{\int_{0}^{\infty} I(t) t \mathrm{~d} t}{\int_{0}^{\infty} I(t) \mathrm{d} t}
$$

where $I(t)$ is the luminescence intensity at time $t$ after the excitation pulse.

Lifetime values are also useful for identifying different environments in a doped glass ceramic sample, according to the phonon energies and decay processes. ${ }^{55}$

In the emission processes, the relationship between the emission intensity $I_{\mathrm{em}}$ and the excitation intensity $I_{\mathrm{ex}}$ is

$$
I_{\mathrm{em}} \propto\left(I_{\mathrm{ex}}\right)^{\mathrm{n}}
$$

where $n$ is the number of infrared photons absorbed per visible photon emitted. Therefore, a plot of $\log I_{\mathrm{em}}$ versus $\log I_{\text {ex }}$ should yield a straight line with slope $n$.

The Judd-Ofelt formalism ${ }^{56,57}$ allows the radiative lifetimes, branching ratios and transition probabilities to be determined and relates them with the environment of the RE ions. ${ }^{58}$ From the room temperature absorption spectra, three parameters are obtained: $\Omega_{2}, \Omega_{4}$ and $\Omega_{6}$. $\Omega_{2}$ is related with short range effects of the glass host, with asymmetry in the vicinity of RE ions and with the covalence between the RE ions and the ligand anions. $\Omega_{2}$ decreases when the host changes from oxide to fluoride. $\Omega_{6}$ is related to the rigidity of the solid host in which the lanthanide ions are situated. The ratio $\Omega_{4} / \Omega_{6}$ is defined as the spectroscopic quality parameter. A decrease in $\Omega_{4}$ implies that the efficiency of the electronic transition is weak.

\section{Glass ceramics for optically active and passive materials}

Transparency is the main required characteristic in nanoglass ceramics for low thermal expansion coefficient materials and transparent materials for optical applications. $^{59-62}$

\section{Transparent nanoglass ceramic materials with low thermal expansion coefficient}

Many optical devices such as telescopes and optical cavities require a substrate material with extremely low thermal expansion coefficient and a high thermal shock resistance. In 1968, the Schott Company patented Zerodur, a nanocrystalline transparent glass ceramic in the $\mathrm{Li}_{2} \mathrm{O}-\mathrm{Al}_{2} \mathrm{O}_{3}-\mathrm{SiO}_{2}$ system, which possesses a coefficient of 


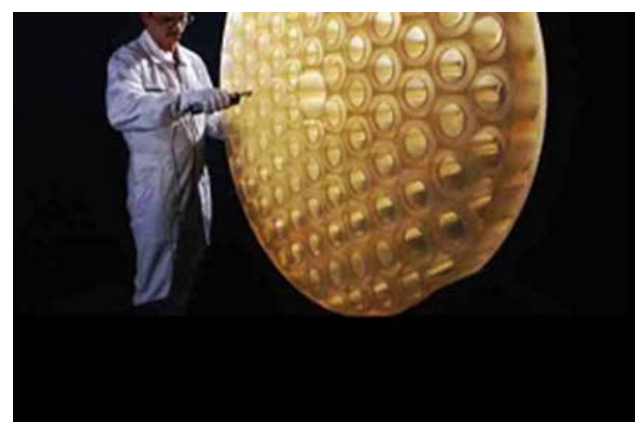

1

thermal expansion close to zero, suitable for the construction of telescope mirror substrates for astronomy ${ }^{63-65}$

4 (Fig. 1); Clearceram-Z (Ohara) is a similar material. In particular, the space telescopes Hubble and the new James Webb, being developed by NASA, are constructed with these glass ceramics.

Ceran (1973) with high temperature stability and durability, high mechanical stability, low thermal conductivity and thermal shock resistance is extensively applied in cooktop panels, and Robax (1979), an extremely heat resistant transparent glass ceramic, is used in fireplaces and stoves.

In 1969, Beall and Duke ${ }^{66}$ described oxide systems based on the crystallisation of spinels, mullite or $\beta$ quartz in a vitreous aluminosilicate matrix. The increasing interest in this system is reflected in more recent reports. ${ }^{67-69}$

More recently, Wurth et al. ${ }^{70}$ have developed nanoglass ceramics from the Robax parent glass, provided by Schott AG, Mainz, Germany. The crystalline phase is a hexagonal high quartz solid solution phase with a nominal composition of $\mathrm{LiAlSi}_{2} \mathrm{O}_{6}$, reaching up to

$580 \mathrm{wt}-\%$ crystals with retention of transparency (Fig. 2). The sizes of the crystals are in the range 16-22 nm for heat treatments at $750^{\circ} \mathrm{C}$ from 4 to $120 \mathrm{~h}$. The viscosity of the glass phase increases during the heat treatments, which decelerates crystal growth and eventually prevents further crystallisation. The crystallisation mechanism of $\mathrm{LiAlSi}_{2} \mathrm{O}_{6}$ in this system has been analysed mainly by TEM techniques ${ }^{71}$ and is explained as follows. Homogeneous precipitation of nanocrystalline $\mathrm{ZrTiO}_{4}{ }^{72}$ which acts as nucleating agent, is accompanied by the formation of an aluminium enriched shell around the $\mathrm{ZrTiO}_{4}$ precipitates, similar to the growth mechanism of $\mathrm{CaF}_{2}$ nanocrystals, which are surrounded by network former oxides. ${ }^{44}$ This $\mathrm{Al}_{2} \mathrm{O}_{3}$ layer at the $\mathrm{ZrTiO}_{4}$-glass interphase decreases the interphase energy, allowing optimum preconditions for nucleation of the secondary phase, $\mathrm{LiAlSi}_{2} \mathrm{O}_{6}$, and retention of its nanometric crystal size. Nuclei formation in lithium-aluminosilicate glass ceramics was previously reported by Sprengard et al., ${ }^{73}$ where $\mathrm{TiO}_{2}$ is segregated from the glass network, acting as a nucleating agent.

\section{Transparent nanoglass ceramic materials for optically active materials}

Nowadays, an interesting and important field of research is focused on the development of optical devices based on materials doped with RE ions for their use in telecommunication systems. In particular, doped phosphate glasses are widely used as host matrices. However, current efforts dedicated to increasing the efficiency of

the devices are focused on finding materials with low phonon energy, in order to reduce the multiphonon nonradiative de-excitation and to improve the cross-sections of the rare earth ions; fluoride and chalcogenide based matrices are the most common choices (Table 1). ${ }^{74-76}$ However, these glasses present difficult melting and forming characteristics, as well as poor chemical durability and mechanical stability.

The development of oxyfluoride glass ceramics offers a better alternative, because of their low phonon energy, optical transparency and RE ion solubility typical of fluoride matrices, allied to the good mechanical, thermal and chemical properties of oxide glasses.

The most relevant publications within this topic are focused on glass ceramics with different crystalline fluoride phases.

$\mathrm{LaF}_{3}$

$\mathrm{LaF}_{3}$ has been extensively studied in oxyfluoride glass ceramics. It has the second lowest phonon energy of the commonly used RE doped matrices (Table 1) and presents a hexagonal crystalline structure. ${ }^{77}$ Moreover, a small crystallographic mismatch exists between $\mathrm{LaF}_{3}$ crystals and $\mathrm{REF}_{3}$ crystals.

Stoch $^{33}$ explained the $\mathrm{LaF}_{3}$ crystallisation on the basis of the cation-cation interaction. The ionicity of $\mathrm{Na}-\mathrm{O}$ bonds is much higher than that of $\mathrm{La}-\mathrm{O}$; thus, the $\left[\mathrm{AlO}_{4}\right]$ tetrahedra tend to bond with $\mathrm{Na}^{+}$for compensating their electrical charge, instead of forming bonds with $\mathrm{La}^{3+}$. However, the existence of $\mathrm{Al}-\mathrm{O}-\mathrm{La}$ bonds allows the segregation and crystallisation of $\mathrm{LaF}_{3}$ from the glass structure.

Crystallisation in glasses within the system $\mathrm{Na}_{2} \mathrm{O}-$ $\mathrm{Al}_{2} \mathrm{O}_{3}-\mathrm{SiO}_{2}-\mathrm{LaF}_{3}$ as determined by DTA has been

Table 1 Table of selected lattice phonon energies of commonly used matrices for $\mathrm{Ln}^{3+}$ doping ${ }^{71-73}$

\begin{tabular}{lr}
\hline Material & Highest phonon energy/cm \\
& \\
\hline Phosphate glass & 1200 \\
Silica glass & 1100 \\
Fluoride glass & 550 \\
Chalcogenide glass & 400 \\
$\mathrm{LaPO}_{4}$ & 1050 \\
$\mathrm{YAG}_{\mathrm{YVO}_{4}}$ & 860 \\
$\mathrm{LaF}_{3}$ & 600 \\
$\mathrm{LaCl}_{3}$ & 300 \\
\hline
\end{tabular}




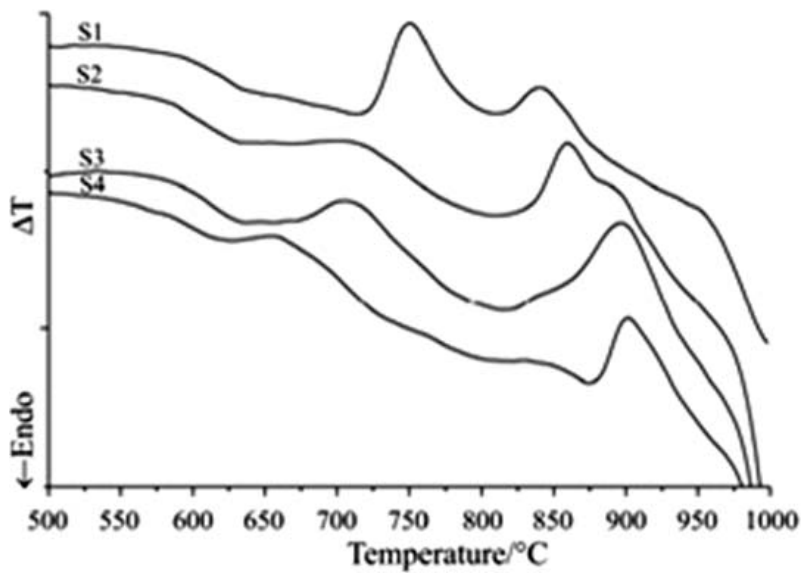

3

discussed in detail. ${ }^{34}$ The glass compositions are (51-60) $\mathrm{SiO}_{2}-(21-26) \mathrm{Al}_{2} \mathrm{O}_{3}-(16-22) \mathrm{Na}_{2} \mathrm{O}-(1-4) \mathrm{LaF}_{3}(\mathrm{~mol}-\%)$. The crystallisation process was identified through exothermic peaks above $T_{\mathrm{g}}$ (Fig. 3). The propension for crystallisation of these glasses was studied from the crystallisation temperatures $T_{\text {cryst }}$, crystallisation enthalpy $\Delta H_{\text {cryst }}$ and thermal stability parameter $\Delta T=T_{\text {cryst }}-T_{\mathrm{g}}$. Heat treatments at the maximum crystallisation temperature of $\mathrm{LaF}_{3}$ were carried out, and the structure and size of the precipitated crystals were studied by XRD and TEM. The crystallisation mechanism of $\mathrm{LaF}_{3}$ was explained through crystallochemical arguments.

(i) silica: increasing silica content increases the viscosity. High silica contents with a fixed ratio $\mathrm{La}_{2} \mathrm{~F}_{6} / 2\left(\mathrm{Al}_{2} \mathrm{O}_{3}+\mathrm{Na}_{2} \mathrm{O}\right)$ produce an increase in $T_{\mathrm{g}}$ and a reduction of heat capacity, $\Delta C_{\mathrm{p}}$, making evident the increase in the glass network strength. In addition, the temperature of the DTA crystallisation peak shifts to higher values, the crystallisation enthalpy $\Delta H_{\text {cer }}$ decreases and the thermal stability index $\Delta T=T_{\text {cryst }}-T_{\mathrm{g}}$ increases, showing the lower propensity for crystallisation of the glass

(ii) alumina: a reduction in alumina content makes $\mathrm{LaF}_{3}$ crystallisation more difficult, except if this reduction is accompanied by increasing amounts of $\mathrm{Na}_{2} \mathrm{O}$ and $\mathrm{LaF}_{3}$

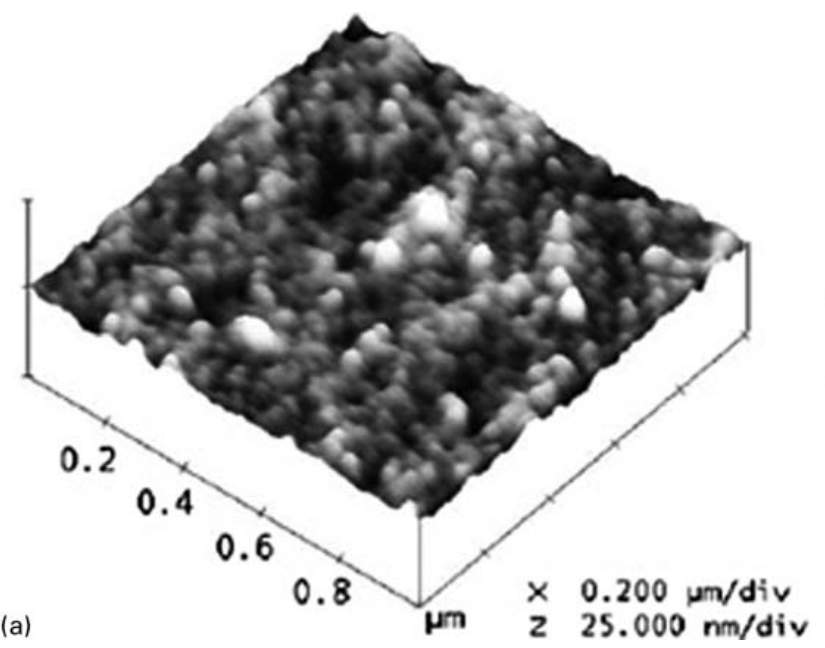

4 (iii) sodium oxide: the $\mathrm{Na}_{2} \mathrm{O} / \mathrm{Al}_{2} \mathrm{O}_{3}$ ratio defines the degree of saturation of $\left[\mathrm{AlO}_{4}\right]$ tetrahedra in the glass network by the $\mathrm{Na}^{+}$ions. When the content of modifier ions is too low, lanthanum is retained by aluminium and $\mathrm{LaF}_{3}$ crystallisation is inhibited

(iv) lanthanum fluoride: lanthanum compensates the electrical charge of the $\left[\mathrm{AlO}_{4}\right]$ and $\left[\mathrm{SiO}_{4}\right]$ tetrahedra only in oxygen bonds which are not saturated by $\mathrm{Na}^{+}$. Thus, the $\mathrm{Na}_{2} \mathrm{O} /$ $\left(\mathrm{SiO}_{2}+\mathrm{Al}_{2} \mathrm{O}_{3}\right)$ ratio gives an idea of the ability of $\mathrm{LaF}_{3}$ crystallisation.

Similar studies were presented in further papers of Sroda et $a l^{78,79}$ in which infrared spectroscopy crystallisation analysis is mainly discussed. The studied compositions are (42-56) $\mathrm{SiO}_{2}-(24-33) \mathrm{Al}_{2} \mathrm{O}_{3}-(16-21)$ $\mathrm{Na}_{2} \mathrm{O}-3 \mathrm{LaF}_{3}(\mathrm{~mol}-\%)$. Nanoglass ceramics were obtained after heat treatments of $20 \mathrm{~min}$ at the corresponding crystallisation peaks with $\mathrm{LaF}_{3}$ crystallising in the range $625-800^{\circ} \mathrm{C}$. This work makes a distinction between first crystallisation state, where $\mathrm{LaF}_{3}$ crystallisation occurs at temperatures lower than the maximum crystallisation peak, and second crystallisation state, where other species like silicates crystallise at higher temperatures. Characterisation by atomic force microscopy was also carried out. Figure 4 shows the fracture surface of the obtained glass ceramics with crystals appearing after $20 \mathrm{~min}$ of treatment at $750^{\circ} \mathrm{C}$.

Reben et $a l^{80}$ performed the structural characterisation by infrared spectroscopy, following the course of $\mathrm{LaF}_{3}$ crystallisation and studying the influence of fluoride content and of different fluorine sources in this process. Additional absorption bands in the glass ceramic respect to the parent glass are observed at 350 , $270,255,206,166,130$ and $100 \mathrm{~cm}^{-1}$, in agreement with the infrared absorption spectra of $\mathrm{LaF}_{3}$.

Hémono et al. ${ }^{81}$ worked on $\mathrm{LaF}_{3}$ nanocrystallisation in glasses of composition $40 \mathrm{SiO}_{2}-30 \mathrm{Al}_{2} \mathrm{O}_{3}-18 \mathrm{Na}_{2} \mathrm{O}-$ $12 \mathrm{LaF}_{3}$ and $55 \mathrm{SiO}_{2}-20 \mathrm{Al}_{2} \mathrm{O}_{3}-15 \mathrm{Na}_{2} \mathrm{O}-10 \mathrm{LaF}_{3}(\mathrm{~mol}-\%)$. In Ref. 82, the former glass was studied by TEM, energy filtered transmission electron microscopy and electron energy loss spectroscopy. Figure $5 a$ shows the elemental distribution map of $\mathrm{Si}$ in the parent glass. Phase separated regions appear much brighter than the matrix, indicating the presence of $\mathrm{Si}$ in phase separated droplets along with $\mathrm{La}$; thus, $\mathrm{La}$ and $\mathrm{Si}$ appear cosegregated

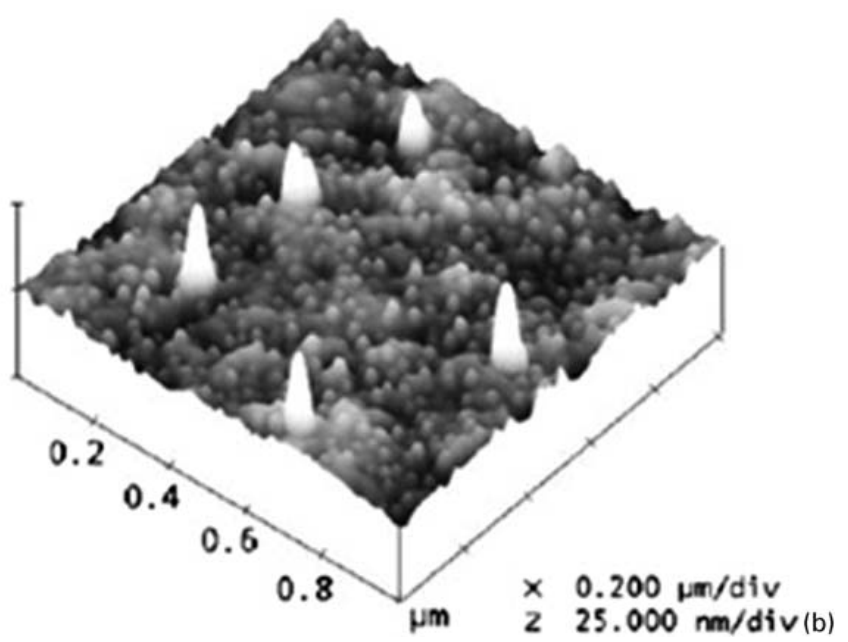



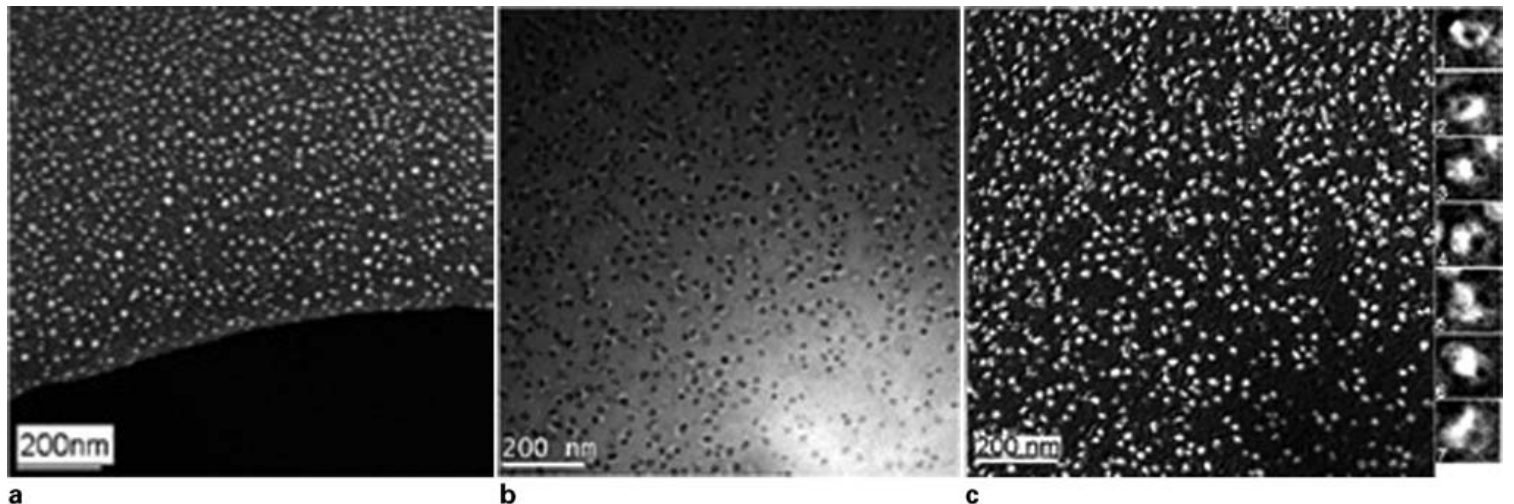

5

within the phase separated droplets. Figure $5 b$ shows the $\mathrm{Si}$ elemental distribution in the glass ceramic. Nanocrystals appear bright and around 2-5 nm larger than the corresponding bright field image. Several magnified images of nanocrystalline precipitates are also shown in Fig. $5 c$, where small dark regions within bright features are identified, confirming the crystallasation of a La rich phase, corresponding to $\mathrm{LaF}_{3}$ crystals from the $\mathrm{La} / \mathrm{Si}$ phase separation nuclei present in the glass. $\mathrm{SiO}_{2}$ enriched environments form around the crystals, hence inhibiting further crystal growth (Fig. 6).

This mechanism suggested by Hémono et al. differs from that of Rüssel in $\mathrm{CaF}_{2}$ containing system, ${ }^{44}$ where phase separation was not detected in the parent glass. Both mechanisms, however, exhibit silica enrichment around the crystals, with the interphase depleted in alumina.

Important contributions to the fluoride crystallisation study have been made with NMR experiments. Muñoz et $a l^{83}$ confirmed the phase separation zones in the glasses studied in Ref. 81 through ${ }^{19} \mathrm{~F}$ NMR. Fluorine in the glasses appears to be involved in $\mathrm{Al}-\mathrm{F}-\mathrm{Na}$ and $\mathrm{La}-\mathrm{F}$ bonds, the latter being precursors of $\mathrm{LaF}_{3}$ nucleation, as discussed in Ref. 82. Thermal treatment of the parent glasses induces the diffusion of fluorine from the glass matrix ( $\mathrm{Al}-\mathrm{F}-\mathrm{Na}$ bonds) into the $\mathrm{La}-\mathrm{F}$ bond enriched nuclei, giving rise to a decrease in the concentration of $\mathrm{Al}-\mathrm{F}-\mathrm{Na}$ and an increase in the number of $\mathrm{La}-\mathrm{F}$ bonds. $\left[\mathrm{SiO}_{4}\right]$ structural units must rearrange in order to facilitate crystal growth and, once a silica enriched

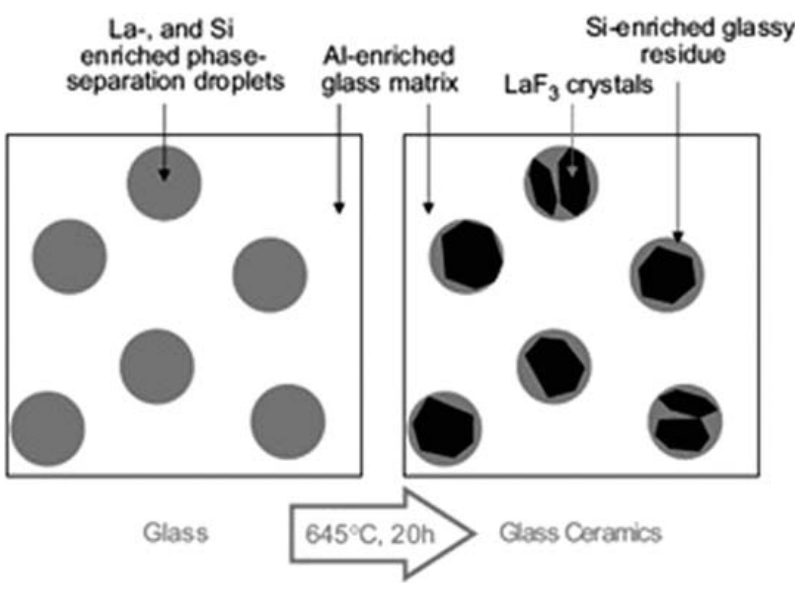

6 region around the crystals is formed, further fluorine diffusion and crystal growth are hindered.

Crystallisation of $\mathrm{LaF}_{3}$ in the system $\mathrm{SiO}_{2}-\mathrm{Al}_{2} \mathrm{O}_{3}-$ $\mathrm{Na}_{2} \mathrm{O}-\mathrm{BaO}-\mathrm{LaF}_{3}$ has also been studied by Youngman and Dejneka ${ }^{84}$ through NMR, demonstrating that fluoride content in the crystalline phase depends on the amount of $\mathrm{SiO}_{2}$ and on the modifier oxide, in this work, $\mathrm{Na}_{2} \mathrm{O}$ or $\mathrm{BaO}$. Analysis of the obtained spectra indicates that the intensity of the La-F signal in crystalline environments in glass ceramics increases with the silica content. Two different signals can be distinguished in the studied glasses: one at $-185 \mathrm{ppm}$, attributed to $\mathrm{Al}-\mathrm{F}$ bonds, and another at $-135 \mathrm{ppm}$, due to $\mathrm{Si}-\mathrm{F}$ bonds. The first signal increases in the glass ceramics containing $\mathrm{Na}_{2} \mathrm{O}$, while the second does so in those with $\mathrm{BaO}$. Signals corresponding to glassy environments decrease in intensity during the progress of crystallisation. Quantitative analysis shows that in $\mathrm{Na}_{2} \mathrm{O}$ containing glass ceramics, the amount of fluoride in $\mathrm{LaF}_{3}$ crystals grows faster than those with $\mathrm{BaO}$, independent of silica content.

Other important reports about the fluorine sites in oxyfluoride glasses and glass ceramics dependent on the composition have been reported by Kiczenski et al. ${ }^{85}$ and Stebbins et al. ${ }^{86}$

\section{Other fluoride crystalline phases}

Rüssel ${ }^{44}$ studied the crystallisation of $\mathrm{CaF}_{2}$ in oxyfluoride glasses following with other fluoride phases. Ritter et al. ${ }^{87}$ reported photo-thermal-refractive glasses in the $\mathrm{Na}_{2} \mathrm{O}-\mathrm{K}_{2} \mathrm{O}-\mathrm{CaO}-\mathrm{CaF}_{2}-\mathrm{Al}_{2} \mathrm{O}_{3}-\mathrm{SiO}_{2}$ system. Glasses are irradiated by ultraviolet light, and the nanocrystallisation of $\mathrm{CaF}_{2}$ takes place only in those irradiated zones.

Bocker et al. ${ }^{88,89}$ studied the crystallisation of $\mathrm{BaF}_{2}$ in glass of composition (mol- $\%)$ : $(100-x)\left(2 \mathrm{Na}_{2} \mathrm{O}-16 \mathrm{~K}_{2} \mathrm{O}-\right.$ $\left.8 \mathrm{Al}_{2} \mathrm{O}_{3}-74 \mathrm{SiO}_{2}\right)-x \mathrm{BaF}_{2}(x=0-6)$, which also leads to an increase in the viscosity near the crystals, forming a silica enriched diffusional barrier. ${ }^{41,79}$ From this composition, Bhattacharyya et al. ${ }^{90}$ studied the mechanism by advanced analytical TEM techniques, including simulations, in which the formation of a $1 \mathrm{~nm}$ wide $\mathrm{SiO}_{2}$ shell around the crystals is confirmed (Fig. 7). Analogous to $\mathrm{CaF}_{2}$ crystallisation, ${ }^{44}$ the parent glass of this system does not present phase separation zones. However, 19 F NMR characterisation of the parent glass with $6 \mathrm{~mol}^{-} \% \mathrm{BaF}_{2}$ gives related structural information. ${ }^{91} \mathrm{~A}$ very small and broad resonance band is detected within the range from -25 to $50 \mathrm{ppm}$, which can be attributed 


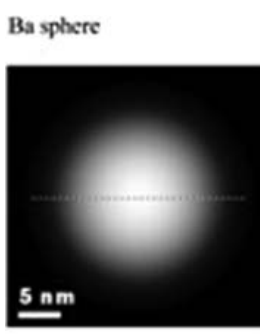

Si hollow sphere
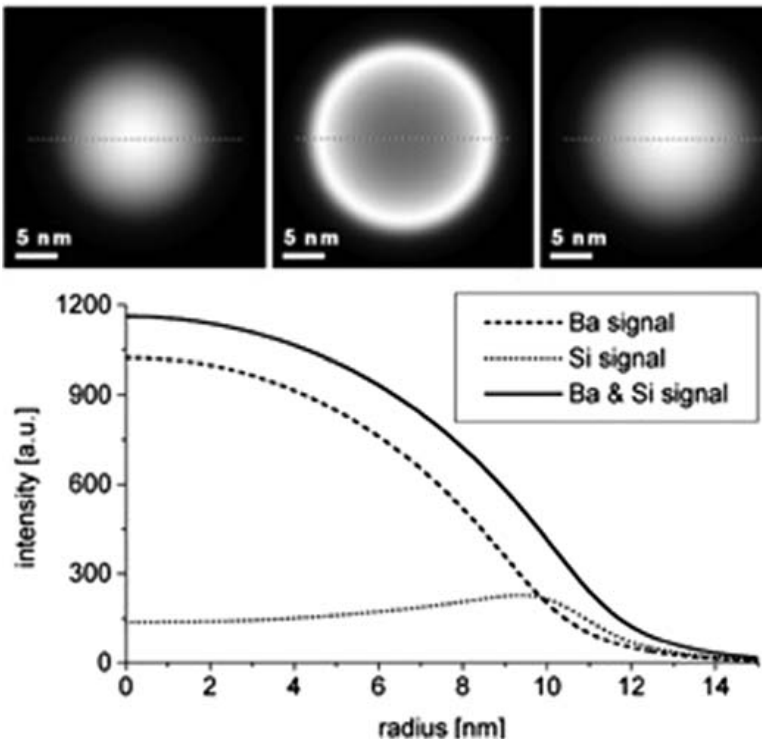

to fluorine in $\mathrm{Ba}-\mathrm{F}$ clusters within an amorphous environment, similar to the results reported by Muñoz et $a l^{83}$ in $\mathrm{LaF}_{3}$ containing glasses. A crystal growth model for the composition studied by Bocker and Rüssel, ${ }^{88}$ was performed through Monte Carlo simulation. ${ }^{44}$ The model fits well the experimental data in a fast increase in initial size without stress development, with a further slowdown of crystal growth, depending on the relaxation time.

Bocker et $a l^{92}$ analysed the effect of viscosity increases in the crystal-glass interphase due to the depletion of barium and fluorine during the course of crystallisation, which decelerates the corresponding diffusion of atoms forming crystals. By combining the second Fickian law with the fluorine concentration profile (Fig. 8), the diffusion coefficient of fluoride in this matrix at a certain temperature is calculated as $4.5 \times 10^{-15} \pm 1 \cdot 1 \times 10^{-15} \mathrm{~m}^{2} \mathrm{~s}^{-1}$ at $580^{\circ} \mathrm{C}$. Bocker et al. ${ }^{93}$ reported for the first time the formation of a high pressure phase, orthorhombic $\mathrm{BaF}_{2}$, due to the effect of compressive stresses. The formation of a viscous layer around the crystals hinders stress relaxation, leading to the orthorhombic high pressure modification of $\mathrm{BaF}_{2}$.

The interest in tetrafluorides increased after $\mathrm{NaYF}_{4}$ was found to be one of the most efficient near infrared (NIR) to visible up-conversion host materials, since its structure offers different sites to incorporate doping ions, and shows phonon energy of $360 \mathrm{~cm}^{-1}$. Liu et al. ${ }^{94}$ studied the nanocrystallisation of this phase in an aluminosilicate glass, and analysed the effects of $\mathrm{Nd}^{3+}$ addition in its crystallisation. A similar study was reported by Sroda, ${ }^{95}$ in the crystallization process of $\mathrm{NaLaF}_{4}$, affected by $\mathrm{Er}^{3+}$ ions. de Pablos-Martín et al. ${ }^{96}$ described the crystallisation mechanism of $\mathrm{NaLaF}_{4}$ and the formation of a diffusional barrier, similar to those work reported in Refs. 44, 82 and 90. Enrichment in $\mathrm{SiO}_{2}$ is evident from TEM techniques. On performing an EELS line scan across a nanocrystal of around $20 \mathrm{~nm}$, a silica concentration profile is developed, showing a shell-like silica distribution (Fig. 9). Muñoz et $a l^{83}$ described the crystallisation mechanism through ${ }^{19} \mathrm{~F}$ NMR measurements (Fig. 10). The

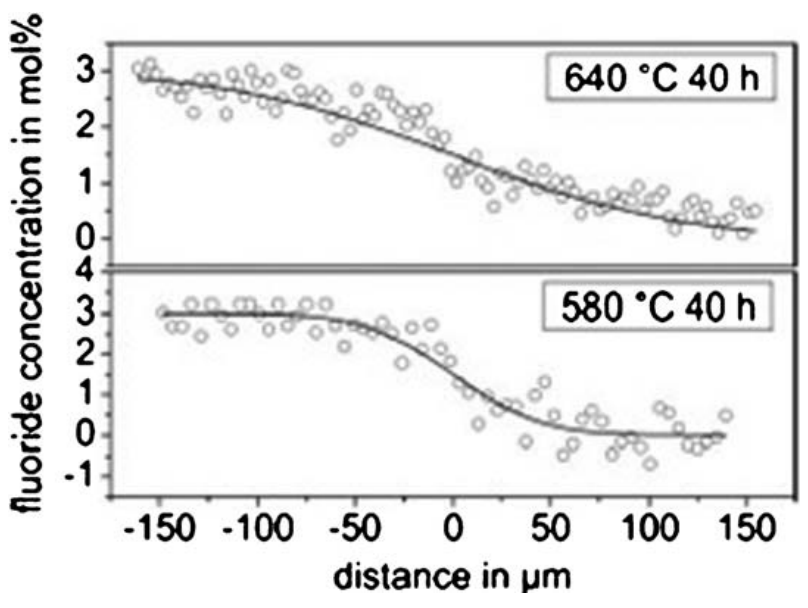

spectrum of the parent glass shows a weak and broad resonance at $-180 \mathrm{ppm}$, assigned to fluorine in $\mathrm{Al}-\mathrm{F}-$ $\mathrm{Na}$ groups, and a larger one centred on $-46 \mathrm{ppm}$, which spreads over the ${ }^{19} \mathrm{~F}$ chemical shift range of $\mathrm{Na}-\mathrm{La}-\mathrm{F}$ bonds, indicating the phase separated regions, which give rise to nanocrystals after heat treatment. For long treatment times, $\mathrm{NaLaF}_{4}$ formation is followed by $\mathrm{NaF}$ precipitation, which can be explained taking into account the silica shell formed around the crystals. Fluorine diffusion from Al-F-Na groups into $\mathrm{NaLaF}_{4}$ crystals occurs only up to a certain treatment time; thereafter fluorine cannot diffuse anymore to form $\mathrm{NaLaF}_{4}$ crystals and $\mathrm{NaF}$ precipitates.

Several questions concerning the fluoride crystallisation mechanism in aluminosilicate systems are still open, even though the topic has been extensively studied in the last 10 years. Fluoride matrices are the key for photonic applications; thus, knowledge of their crystallisation mechanisms, ability of crystallisation and thermodynamic parameters depending on glass composition must be fully understood.

To build a general vision of the analysed crystallisation mechanisms of optically passive and active glass ceramics, we return to the two trends of the crystallisation study. The basis of Stoch and Sroda et al. should be used from the very beginning of the study, since this trend is based on theoretical aspects, such as crystallisation enthalpies, bond ionicities, heat capacities and thermal stability indices. Undoubtedly, this study allows the crystallisation mechanism to be predicted. However, a deeper knowledge of the structure and composition of the intherphases formed between glass matrix and crystal, and their evolution during crystallisation as suggested by Rüssel et al., is necessary. Both approaches represent the basis of a better understanding of crystallisation phenomena in non-isochemical systems in general. They foster the future development of glass ceramics hosting functional nanocrystalline precipitates.

\section{RE elements as doping agents in fluoride containing nanoglass ceramics}

RE elements have been widely used to activate luminescent and photonic materials based on the properties of their f-shell electrons. Liu and Jacquier ${ }^{97}$ have revised the progress in this field, including the 

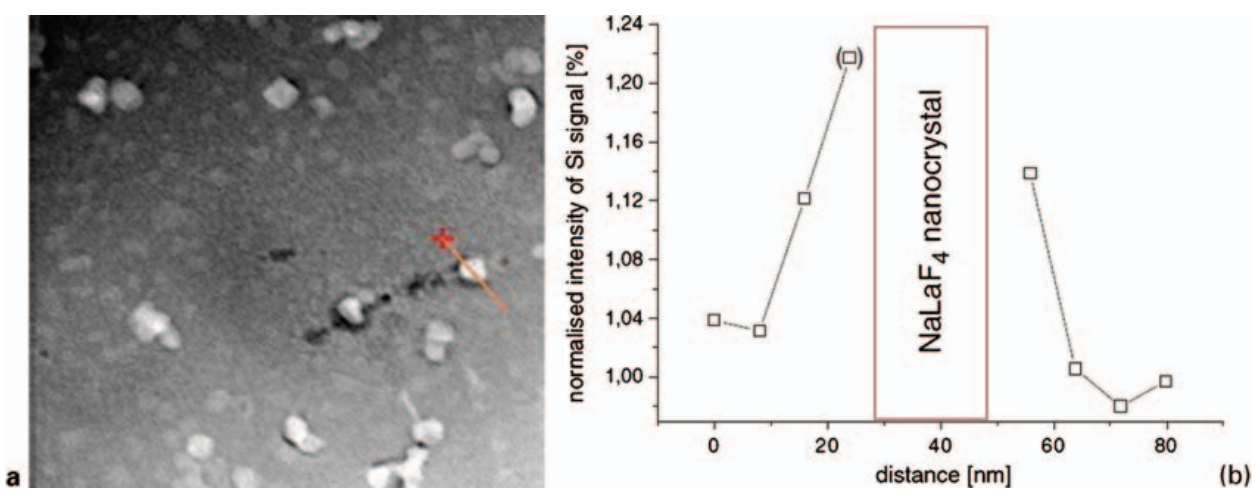

9

principles required to develop and characterise optical materials.

Transparent glass ceramics can be used as active optical devices when they possess the appropriate characteristics for hosting lanthanide ions, thereby allowing the desired optical emissions. In general, a crystal-like environment leads to higher cross-sections, important in the fabrication of more compact devices. Lanthanide ions tend to substitute the cations in the crystalline phase, instead of remaining in the glass matrix. ${ }^{98}$ Thus, the optical and mechanical properties of these glass ceramics are the result of combining the features of the glass matrix and the crystalline phases.

The crystalline phase must fulfil certain criteria: (1) to have low phonon energy in order to avoid non-radiative relaxation channels due to excited state energy transfers by phonons, thereby reaching longer lifetimes and higher luminescence efficiencies (Table 1); (2) to be a good host for $\mathrm{RE}$ elements, e.g. $\mathrm{La}^{3+}$ radius is similar to those of lanthanides, facilitating its substitution in the $\mathrm{LaF}_{3}$ lattice; and (3) to be thermally stable.

The luminescence properties of doped glass ceramics are related to the microstructure developed during crystallisation, wherein the absorption and scattering are two important phenomena. Location of doping agents into the crystals enhances the radiative decay processes. Some important factors to take into account when using REs as dopants are the lifetime of their excited states and the non-radiative decay channels, which depend on the environment and on their excitation energies.

The doping agent must exhibit certain characteristics, such as emission bands at interesting wavelengths for applications, excitation with an available and affordable source, and having one or more metastable electronic levels.

To confirm the inclusion of the dopant ions into the crystals, certain RE ions are used as structural probes. This is the case of $\mathrm{Eu}^{3+}$, which is widely studied not only in glassy ${ }^{99-101}$ and crystalline ${ }^{102,103}$ matrices, but also in glass ceramics. ${ }^{104}$ The ${ }^{5} \mathrm{D}_{0} \rightarrow{ }^{7} \mathrm{~F}_{2}$ transition is electrical dipole allowed and sensitive to the local environment, while the ${ }^{5} \mathrm{D}_{0} \rightarrow{ }^{7} \mathrm{~F}_{1}$ transition is magnetic dipole allowed, and independent of the host matrix. The fluorescence intensity ratio $R$ of ${ }^{5} \mathrm{D}_{0} \rightarrow{ }^{7} \mathrm{~F}_{2}$ to ${ }^{5} \mathrm{D}_{0} \rightarrow{ }^{7} \mathrm{~F}_{1}$ transitions is used to establish the degree of both
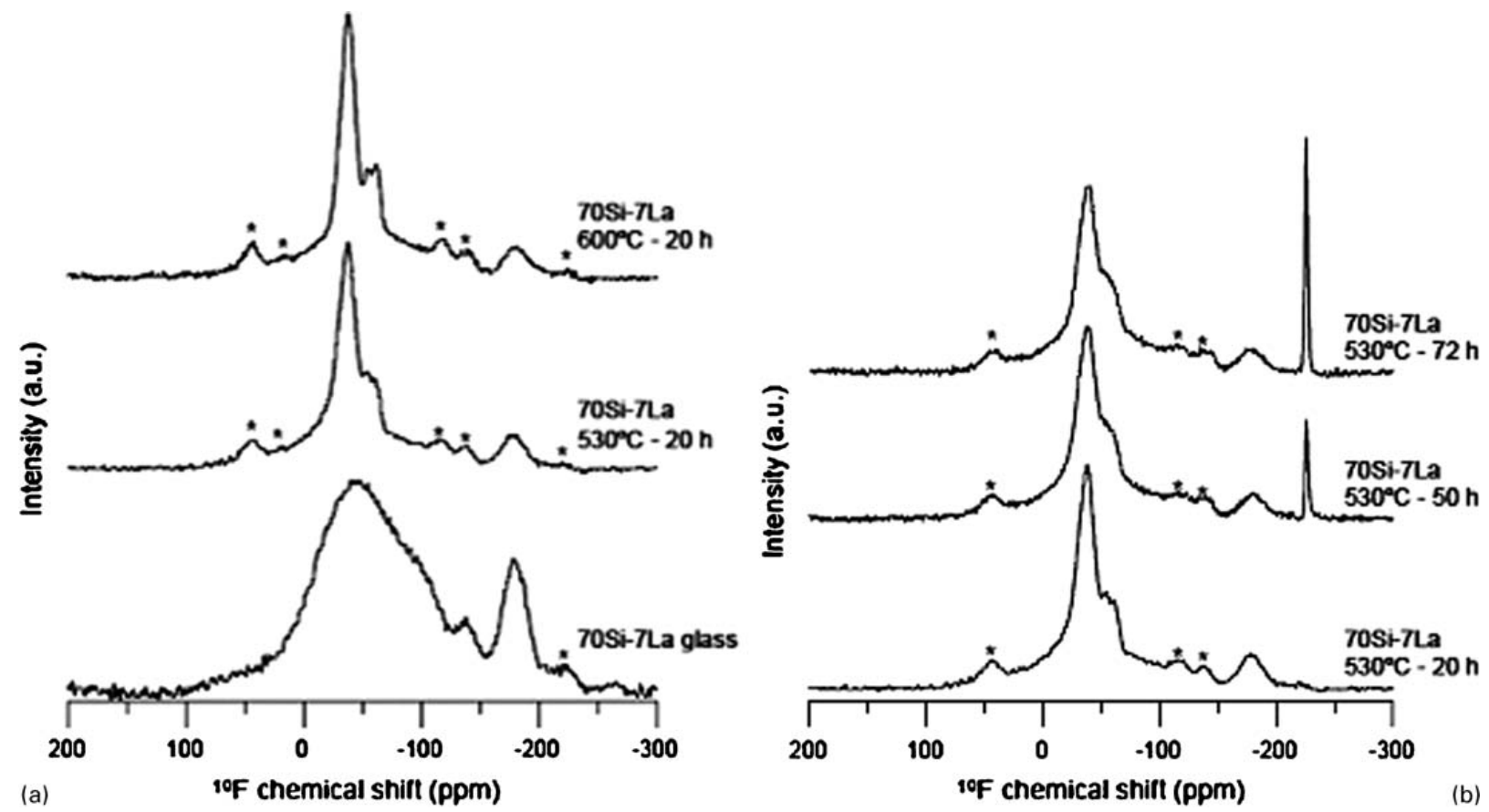

10 


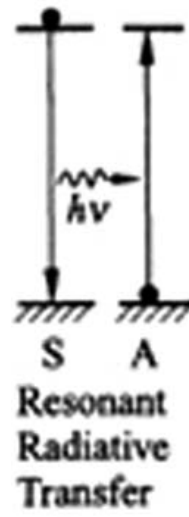

(a)

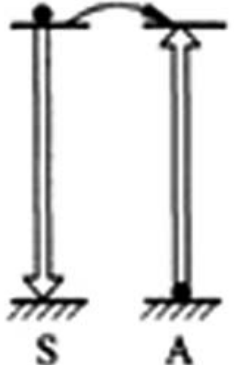

Resonant

Non-tadiative Transfer

(b)

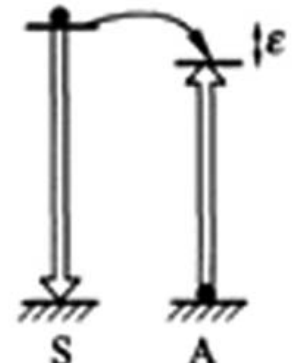

Phonon-assisted

Non-radiative

Transfer : $\varepsilon$ is

Energy

Mismatch

(c)

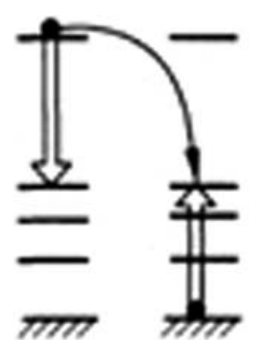

$\mathbf{S}=\mathbf{A} \quad \mathbf{A}$

Cross-Relaxation

between Two

Identical lons:

$\mathbf{S}=\mathbf{A}$

(d) asymmetry in the vicinity of $\mathrm{Eu}^{3+}$ ions and $\mathrm{Eu}-\mathrm{O}$ covalence. ${ }^{105}$ The emission intensity of the ${ }^{5} \mathrm{D}_{0} \rightarrow{ }^{7} \mathrm{~F}_{2}$ electrical dipole transition is more intense in nonsymmetric sites. $R$ also depends on the Judd-Ofelt parameter $\Omega_{2}$, which is used to describe the short range effects. The higher the value of $R$, the lower the symmetry of $\mathrm{Eu}^{3+}$ ions and more covalent the $\mathrm{Eu}-\mathrm{O}$ bond. ${ }^{106,107}$

\section{Up- and down-conversion processes Up-conversion process}

Up-conversion (UC) emission is an anti-Stokes process, in which low excitation photons produce photons of higher energy. ${ }^{108}$ Auzel $^{109}$ reviewed the UC processes taking place in doped systems through different types of energy transfer between pairs of ions: radiative, nonradiative, resonant and phonon assisted transfer. For a radiative energy transfer (Fig. 11a), photons are emitted by the sensitiser ions $\mathrm{S}$ and are then absorbed by the activator ions $\mathrm{A}$ within a photon travel distance.
The factors to be controlled in energy transfer processes leading to UC emission include: (1) a phonon energy of the host matrix which is low enough to allow radiative decays; (2) the RE ion concentration, since an increase of the dopant ion concentration reduces the distances between ions and the energy transfer probability is enhanced; ${ }^{110}$ (3) temperature, since low temperatures $(10-70 \mathrm{~K})$ minimise the network vibrations, and thus the non-radiative decay processes.

UC occurs through a photon avalanche (PA) mechanism. PA was discovered in $\mathrm{Pr}^{3+}$ based infrared quantum counters by Chivian et al. ${ }^{111}$ Joubert made a complete description of the theoretical treatment of PA process. ${ }^{112,113}$ There are two main characteristics of PA: (1) the pump wavelength is only resonant between a metastable state and a higher energy level; in other words, the energy of the excited state exceeds that of the pump photon; and (2) below a power threshold the up-converted fluorescence intensity is weak; above it, the fluorescence increases by orders of magnitude and
E

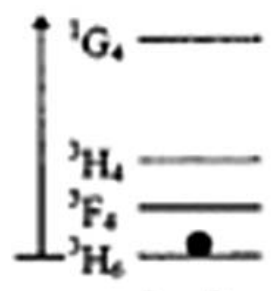

Ion 2

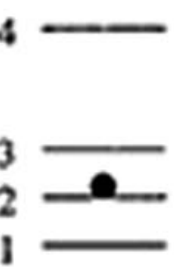

Ion I

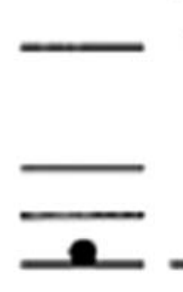

Ion 3
E

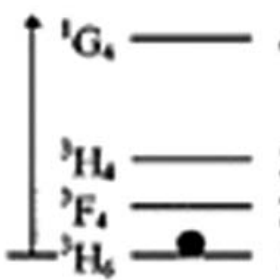

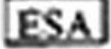

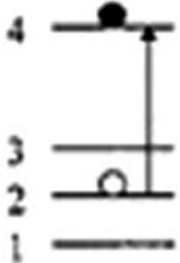

Ion 1 Ion 3

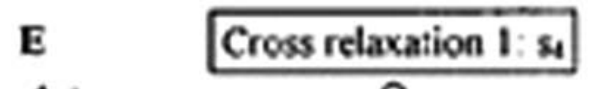

loa 2

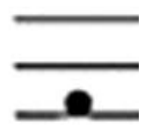

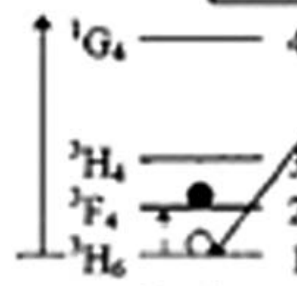

Ion 2

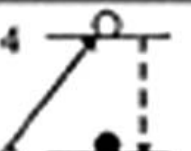

(1)

1

Ion 1

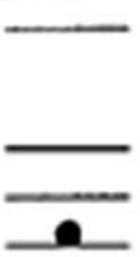

Ion 3
E

Cross relaxation 2:5s

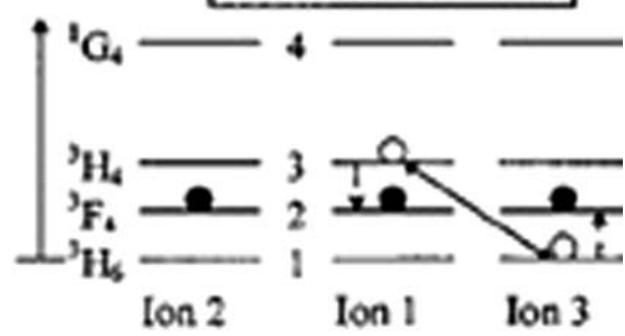

12 
(a)

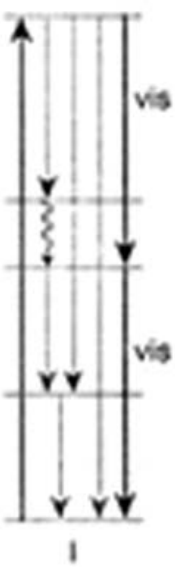

(b)

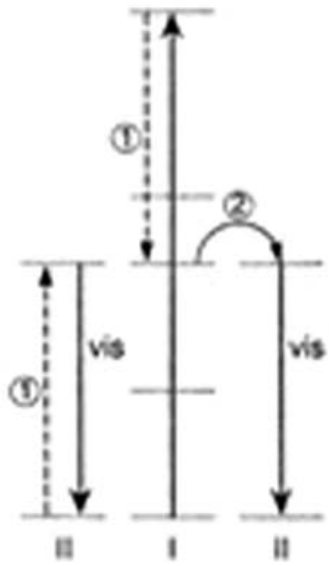

(c)

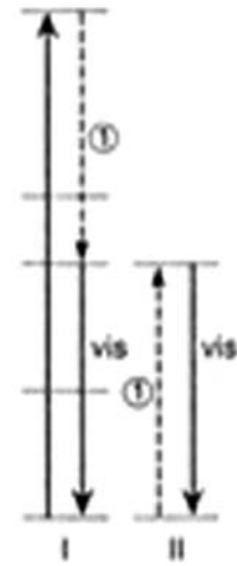

(d)

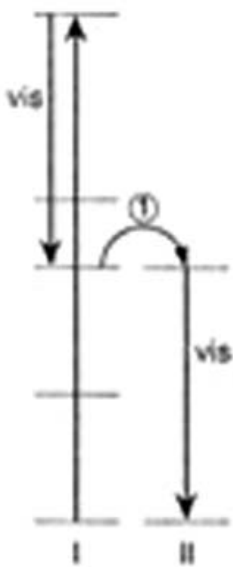

13

the pump light is strongly absorbed. Qualitatively, this process can occur under the following conditions: (1) the first absorption is weak, so the excitation should not be at the wavelength of the corresponding absorption peak, but at the tail of the absorption band; (2) the intermediate level has a long lifetime compared with the highest level; and (3) the cross-relaxation energy transfer between the highest level and the ground level is faster than any other relaxation mechanism. Figure 12 shows schematically the photon avalanche process in $\mathrm{Tm}^{3+}$.

Finally, there are interesting advances in Monte Carlo modelling within this field, which can help to elucidate the emission mechanisms via the simulation of UC luminescence results. ${ }^{114}$

\section{Down-conversion processes}

In contrast to UC, down-conversion (DC) processes a high energy photon leads to the emission of visible or NIR photons (quantum cutting) (Fig. 13a). ${ }^{115,116}$ In order to avoid ultraviolet and infrared emissions, energy transfer processes between the different ions are required (Fig. 13b-d).

One main application of this phenomenum is within the photovoltaic energy field (Fig. 14), since DC emissions avoid the current thermalisation losses in the crystalline silicon solar cells. ${ }^{117} \mathrm{Yb}^{3+}$ is the most used $\mathrm{RE}$ ion for this purpose, since it has an optical transition at about $1000 \mathrm{~nm}$, just over the silicon gap. DC mechanisms involving $\mathrm{Yb}^{3+}$ ions are generally similar: a codopant $\mathrm{RE}$ ion acts as a sensitiser, receiving the excitation wavelength, generally in the blue range, then transferring energy to the $\mathrm{Yb}^{3+}$ ions, which act as activators, emitting about $1000 \mathrm{~cm}^{-1}$. The visible emission of the sensitiser, generally in the range from green to red, is also obtained.

\section{Luminescence, UC and DC in fluoride glasses and crystals}

Phosphate glasses were the first studied hosts of RE ions ${ }^{18-120}$ because of their idoneous refractive index, high transparency to ultraviolet light, high gain, good thermo-optical performance, low rupture strength and sufficient chemical durability. Schott Glass Technologies (USA) developed the glass LG-750, which is a well known commercial laser in the system $\mathrm{P}_{2} \mathrm{O}_{5}-\mathrm{K}_{2} \mathrm{O}-\mathrm{BaO}-\mathrm{Al}_{2} \mathrm{O}_{3}$ doped with a significant amount of $\mathrm{Nd}_{2} \mathrm{O}_{3}$. The glass is of great significance in the market for high average energy and high peak power solid state laser applications (Ref. 121 and references Therein). The drawbacks of these systems are the short lifetime of the excited states and non-radiative decay paths. Fluoride glasses with low matrix vibrational energies have been further developed which enhance the efficiency of the radiative decay.

Within the fluoride and oxyfluoride glass systems, it is worth citing the review of Tran et al. ${ }^{122}$ which is focused on heavy metal fluoride glasses and $\mathrm{AlF}_{3}$ based glasses. Allen et al. $^{123}$ studied $\mathrm{Tm}^{3+}$ doped ZBLAN fibre glasses $\left(\mathrm{ZrF}_{2}-\mathrm{BaF}_{2}-\mathrm{LaF}_{3}-\mathrm{AlF}_{3}-\mathrm{NaF}\right)$ obtaining infrared emission from the excitation at $790 \mathrm{~nm}$. By measuring the power output versus absorbed pump power at $790 \mathrm{~nm}$, efficiencies of $35 \%$ were achieved. Murtagh et al. ${ }^{124}$ described the phenomenum of laser cooling from the a

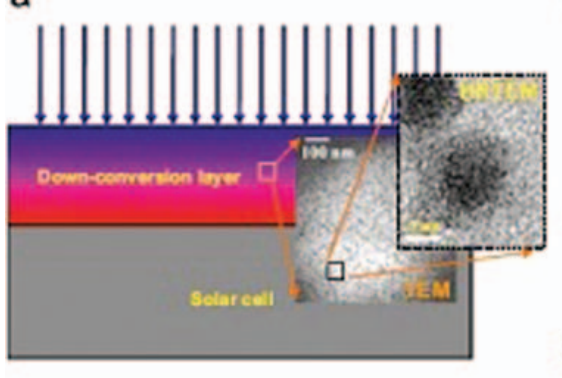

b

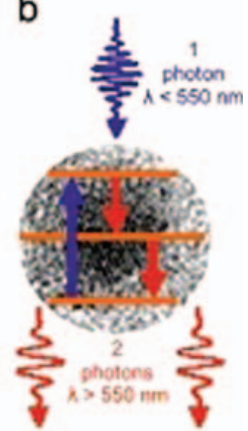

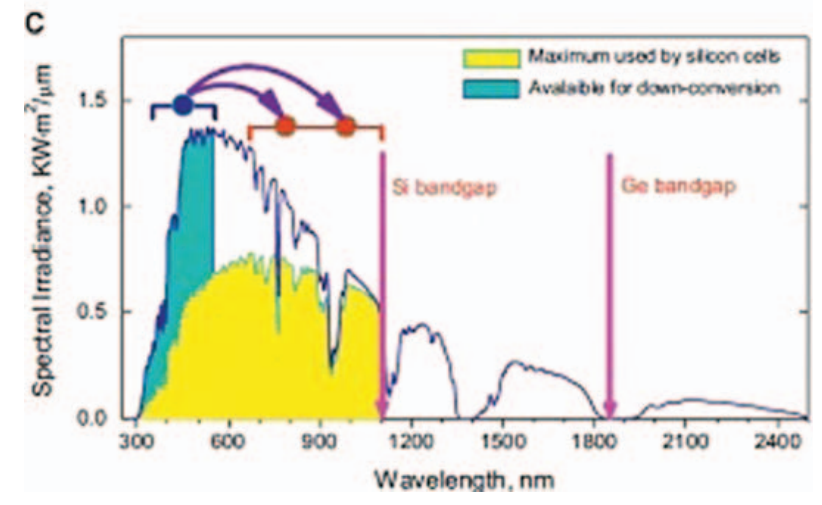

14 
fluorescence properties of $\mathrm{Yb}^{3+}$ doped ZBLANPb glasses. Temperature drops of $16 \mathrm{~K}$ have been observed in fibre samples.

Tanabe et al. ${ }^{125}$ doped fluoride glasses with $\mathrm{Tm}^{3+}$, relating the UC luminescence directly with the JuddOfelt parameters. Seeber et al. ${ }^{126}$ dealt with $\mathrm{Pr}^{3+}$ doped fluorozirconates, fluorindates and fluorophosphates, and concluded that fluorozirconates are the most suitable matrices for applications in optical devices, since fluorindates tend to easily crystallise and fluorophosphates present a high photonic energy. They also focused on $\mathrm{Nd}^{3+}$ doped fluorophosphate glasses, ${ }^{127}$ analysing the dependence of the $\mathrm{Nd}^{3+}$ emission at $1.06 \mu \mathrm{m}$ on the chemical structure of the glass matrix.

One interesting field using glassy matrices is the generation of white light from multidoped glasses. Multicolour and white light can be achieved by combining the emission of the three primary colours, red, green and blue, from glasses doped with multiple RE ions. An optimum codoping strategy requires an energy transfer between the involved ions, so the emission radiation of one is absorbed for the other ion to be excited to a higher level, producing more intensive emission. Recently, Lakshminarayana et al. ${ }^{128}$ developed $\mathrm{Tm}^{3+} / \mathrm{Dy}^{3+}$ codoped oxyfluoridegermanate glasses, which show white light emission after excitation at $350 \mathrm{~nm}$. These authors ${ }^{129}$ also analysed the DC emission in oxyfluoride glasses of composition $50 \mathrm{GeO}_{2}-10 \mathrm{~B}_{2} \mathrm{O}_{3}-20 \mathrm{ZnO}-20 \mathrm{LaF}_{3}-0 \cdot 5(\mathrm{RE}) \mathrm{F}_{3} \cdot x$ $\mathrm{YbF} 3 \quad(\mathrm{RE}=\mathrm{Pr}, \mathrm{Tb}, \mathrm{Tm} ; \quad x=0-30 \mathrm{~mol}-\%)$. Energy transfer from one of the codopant $\mathrm{RE}^{3+}$ ions to two $\mathrm{Yb}^{3+}$ ions leads to an infrared emission at 950-1100 nm, with efficiencies of $200 \%$.

The sol-gel method offers the advantage of permitting the incorporation of a higher dopant concentration without loss of amorphous character. Doped fluoride glasses and crystals obtained by this method are reported in Refs. 130-132. Sol-gel materials are obtained as thin films and coatings, in contrast to bulk materials prepared by the melting method.

Concerning fluoride crystalline systems, the works of Hewes ${ }^{133}$ and Guggenheim and Johnson ${ }^{134}$ are of particular importance, in which the UC emissions of different RE ions in fluoride crystals are analysed. The observation of stimulated emission by UC at $77 \mathrm{~K}$ was reported in 1971 by Johnson and Guggenheim ${ }^{135}$ in $\mathrm{BaY}_{2} \mathrm{~F}_{8}$ codoped with $\mathrm{Yb}^{3+} / \mathrm{Er}^{3+}$ and $\mathrm{Yb}^{3+} / \mathrm{Ho}^{3+}$. Joubert ${ }^{109}$ summarised the RE doped materials in which PA has been observed, as well as crystalline UC lasers, in which $\mathrm{LaBr}_{3}, \mathrm{LaCl}_{3}, \mathrm{LaF}_{3}, \mathrm{LiYF}_{4}, \mathrm{KYF}_{4}, \mathrm{CdF}_{2}$ and $\mathrm{CaF}_{2}$ are included.

$\mathrm{LaF}_{3}$ is one of the most studied crystalline phases for doping with lanthanides. Weber ${ }^{55}$ studied the $\mathrm{LaF}_{3}: \mathrm{Er}^{3+}$ system, whereas Collings and Silversmith ${ }^{136}$ and $\mathrm{Lim}^{137}$ treated the $\mathrm{LaF}_{3}: \mathrm{Tm}^{3+}$ material. The works of Chivian et al. ${ }^{111}$ related to PA process in $\operatorname{Pr}^{3+}: \mathrm{LaCl}_{3}$ were followed by others with $\mathrm{Sm}^{3+}, \mathrm{Nd}^{3+}$ and $\mathrm{Tm}^{3+}$ as doping agents in crystalline halides. ${ }^{138-141}$ Macfarlane et $a l .{ }^{142}$ carried out UC measurements in crystalline fluorides doped with $\mathrm{Er}^{3+}$ and $\mathrm{Nd}^{3+}$.

Mixed crystalline fluorides are becoming interesting because of the multisite nature of the crystalline lattice, meaning that RE ions can occupy various nonequivalent sites in the lattice; examples include $\mathrm{LiYF}_{4}: \mathrm{Sm}^{3+},{ }^{143} \mathrm{KLaF}_{4}: \mathrm{Sm}^{3+},{ }^{144} \mathrm{NaLaF}_{4}: \mathrm{Ln}^{3+}(\mathrm{Ln}=$ Ce, Pr, Nd, Sm, Eu, Gd, Tb, Dy, Ho, Er, Tm $)^{145}$ and
$\mathrm{NaLaF}_{4}: \mathrm{Er}^{3+} \cdot{ }^{146}$ The location of the energy levels of lanthanides ions by photo- and thermo-luminescence were studied in $\mathrm{NaGdF}_{4}: \mathrm{Tm}^{3+}, \mathrm{NaGdF}_{4}: \mathrm{Nd}^{3+}, \mathrm{NaLaF}_{4}: \mathrm{Tm}^{3+}$ and $\mathrm{NaLaF}_{4}: \mathrm{Nd}^{3+},{ }_{147}$ and $\mathrm{NaYF}_{4}: \mathrm{Ln}^{3+} .148,149$

Non-conventional methods have been used to obtain RE doped crystals including the core-shell method, where Diamente et al. ${ }^{150}$ reported the development of core/shell nanoparticles of $\mathrm{LaF}_{3}: \mathrm{Tm}^{3+} / \mathrm{LaF}_{3}$ which shows a high photoluminescence at $1.47 \mu \mathrm{m}$. Li et al. ${ }^{151}$ employed hydrothermal synthesis to synthesise $\mathrm{Eu}^{3+}$ doped $\mathrm{LnF}_{3}$ crystals in an aqueous medium, obtaining different morphologies. The coprecipitation method was used to obtain $\mathrm{Eu}^{3+}$ doped $\mathrm{NaGdF}_{4}$ and $\mathrm{KGdF}_{4}$ crystals. ${ }^{152,153}$

The main advantage of these works is the low vibrational energies of fluoride matrices. However, the high cost and the difficulty of obtaining extended crystalline matrices represents a real limit to scale-up of these materials.

\section{Luminescent processes in oxyfluoride glass ceramics}

\section{Wang and Ohwaki's composition}

The first publication on oxyfluoride glass ceramics was by Wang and Ohwaki in 1993, ${ }^{1}$ who reported the composition $30 \mathrm{SiO}_{2}-15 \mathrm{Al}_{2} \mathrm{O}_{3}-20 \mathrm{CdF}_{2}-4 \mathrm{PbF}_{2}-10 \mathrm{YbF}_{3}-$ $1 \mathrm{ErF}_{3}(\mathrm{~mol}-\%)$. The authors ascribed the crystalline phase to $\mathrm{Pb}_{\mathrm{x}} \mathrm{Cd}_{1-\mathrm{x}} \mathrm{F}_{2}$, but further investigations suggested that their results could be compatible with $\mathrm{PbF}_{2}$, $\mathrm{CdF}_{2}$ or a $\mathrm{Pb}_{\mathrm{x}} \mathrm{Cd}_{1-\mathrm{x}} \mathrm{F}_{2}$ solid solution.

Two further works have played a decisive role to clarify this topic. Tikhomirov et al. ${ }^{154}$ confirmed the crystallisation of $\mathrm{PbF}_{2}$ from the glass composition $32 \mathrm{SiO}_{2}-12 \cdot 5 \mathrm{AlO}_{1 \cdot 5}-31 \cdot 5 \mathrm{CdF}_{2}-18 \cdot 5 \mathrm{PbF}_{2}-5 \cdot 5 \mathrm{ZnF}_{2}-$ $3 \cdot 5 \mathrm{ErF}_{3}(\mathrm{~mol}-\%)$, through $\mathrm{EDS}$ data, and suggested a model for nucleation and growth of this phase. The parent glass was heat treated at $T_{\mathrm{g}}\left(390^{\circ} \mathrm{C}\right)$ for $3 \mathrm{~h}$, indicating the presence of $2.5 \mathrm{~nm}$ orthorhombic $\mathrm{PbF}_{2}: \mathrm{Er}^{3+}$ crystallites, which forms nucleation centres. When this glass ceramic is heat treated at temperatures above $350^{\circ} \mathrm{C}$, the transformation from orthorhombic $\mathrm{PbF}_{2}: \mathrm{Er}^{3+}$ to cubic $\mathrm{PbF}_{2}: \mathrm{Er}^{3+}$ takes place, and further heat treatment contributes to the growth of $\mathrm{PbF}_{2}: \mathrm{Er}^{3+}$ cubic crystals. $\mathrm{Er}^{3+}$ occupies $\mathrm{Pb}^{2+}$ sites, creating a cation vacancy, which is charge compensated by additional $\mathrm{F}^{-}$and resulting in distortion of the cubic fluorite structure. Beggiora et al. ${ }^{155}$ attributed this controversy to the low crystalline fraction and line broadening of the X-ray peaks due to the nanometric size of the crystals. They studied the glass composition $30 \mathrm{SiO}_{2}-15 \mathrm{Al}_{2} \mathrm{O}_{3}-29 \mathrm{CdF}_{2}-17 \mathrm{PbF}_{2}-5 \mathrm{ZnF}_{2}-4 \mathrm{ErF}_{3}$ (mol- $\%$ ), through computer simulation methods, concording with Tikhomirov et al. with regard to an $\mathrm{F}^{-}$ interstitial compensation mechanism, in which $\mathrm{Er}^{3+}$ substitutes $\mathrm{Pb}$ in $\mathrm{PbF}_{2}$ crystal; however, they further suggested a coexistence of cubic and trigonal structures, which could explain the distortion of the fluorite structure reported by Tikhomirov et al. Thus, these works show that $\mathrm{Er}^{3+}$ is located in a $\mathrm{PbF}_{2}$ fluorite or distorted fluorite structure, rather than in the $\mathrm{Pb}_{\mathrm{x}} \mathrm{Cd}_{1-\mathrm{x}} \mathrm{F}_{2}$ solid solution reported by Wang and Ohwaki.

Recently, Hass et al., ${ }^{156}$ in collaboration with Rüssel, studied glass ceramics from the composition $21 \cdot 1 \mathrm{SiO}_{2}-$ $7 \mathrm{Al}_{2} \mathrm{O}_{3}-6 \cdot 5 \mathrm{~B}_{2} \mathrm{O}_{3}-14 \cdot 3 \mathrm{CdF}_{2}-21 \cdot 0 \mathrm{PbF}_{2}-11 \cdot 0 \mathrm{PbO}-7 \cdot 6 \mathrm{CdO}-$ $11 \cdot 0 \mathrm{YbF}_{3}-0 \cdot 5 \mathrm{ErF}_{3} \quad(\mathrm{~mol}-\%)$ through anomalous small 

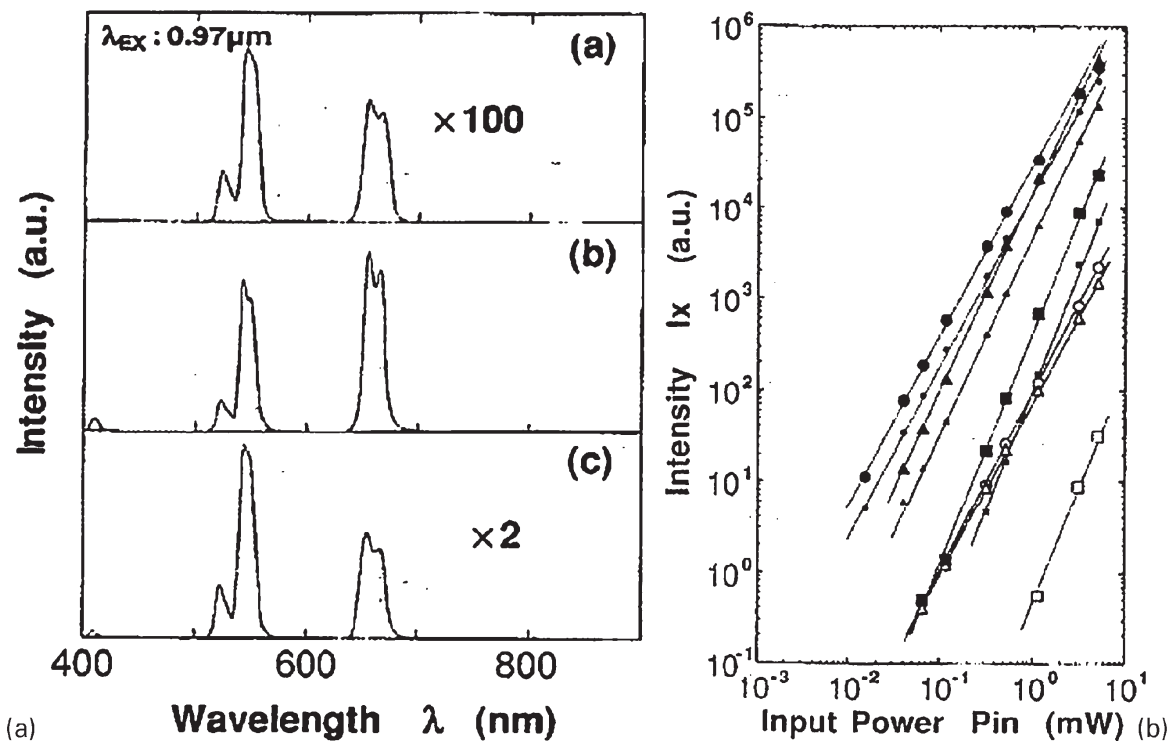

angle X-ray scattering. This work confirms the previous studies of Tikhomirov et al. and Beggiora et al., concluding that the composition of the precipitated crystals in the glass ceramics obtained at $405^{\circ} \mathrm{C}$ during $30 \mathrm{~min}$ is $\mathrm{Pb}_{17} \mathrm{Yb}_{17} \mathrm{Er}_{2} \mathrm{~F}_{64}$.

$\mathrm{PbF}_{2}$ has a possess very low phonon energy, about $250 \mathrm{~cm}^{-1}$, and doping with $\mathrm{Yb}^{3+} / \mathrm{Er}^{3+}$ ions generates an $\mathrm{UC}$ emission which is more brilliant than those observed in the fluoride glass of composition $35 \mathrm{~A}^{1 F_{3}}-14 \mathrm{YbF}_{3}$ $1 \mathrm{ErF}_{3}-20 \mathrm{PbF}_{2}-5 \mathrm{MgF}_{2}-15 \mathrm{CaF}_{2}-10 \mathrm{BaF}_{2}(\mathrm{~mol}-\%)$, which was the most efficient infrared UC material until $1993 .{ }^{157}$ Figure 15 shows the UC spectra and the UC intensities of the precursor glass at 410, 550 and $660 \mathrm{~nm}$ after excitation at $972 \mathrm{~nm}$; the glass ceramic and an aluminofluoride glass are shown for comparison.

The use of amplifiers in the range $1 \cdot 3-1 \cdot 5 \mu \mathrm{m}$ triggered research on doped materials for optics waveguides. A ${ }^{1} \mathrm{G}_{4} \rightarrow{ }^{3} \mathrm{H}_{5}$ transition of $\operatorname{Pr}^{3+}$ is used in most of these devices, but a main drawback is the high phonon energy of the oxide host. Thus, the use of oxyfluoride glass ceramics seems to be ideal.

Wang and Ohwaki's glass ceramic was the starting point for the design of matrices for $\mathrm{Pr}^{3+}$ ions to retain the transmission at $1300 \mathrm{~nm}$, avoiding the presence of $\mathrm{Yb}^{3+}$, which make this emission difficult. Tick et al. ${ }^{158}$ substituted $\mathrm{YbF}_{3}$ for $\mathrm{YF}_{3}$ and for a mixture $\mathrm{YF}_{3} / \mathrm{ZnF}_{2}$ in glasses of composition $30 \mathrm{SiO}_{2}-15 \mathrm{Al}_{2} \mathrm{O}_{3}-29 \mathrm{CdF}_{2}-$ $17 \mathrm{PbF}_{2}-4 \mathrm{YF}_{3}-5 \mathrm{ZnF}_{2}$ and $30 \mathrm{SiO}_{2}-15 \mathrm{Al}_{2} \mathrm{O}_{3}-29 \mathrm{CdF}_{2}-$ $22 \mathrm{PbF}_{2}-4 \mathrm{YF}_{3}(\mathrm{~mol}-\%)$. After heat treatment at around $470^{\circ} \mathrm{C}$, from periods of a few minutes to more than $12 \mathrm{~h}$, a crystalline phase of $\mathrm{CdF}_{2}$ with a fluorite type structure precipitates and corresponds to $\mathrm{CdF}_{2}$. Crystal sizes between 9 and $18 \mathrm{~nm}$ and a volume fraction of $20-30 \%$ were estimated from XRD and TEM. Evidence of the presence of $\mathrm{Pr}^{3+}$ ions in crystals is provided by the following: (1) after excitation at $1.02 \mu \mathrm{m}$, glassy samples did not present fluorescence; (2) the lifetime of the transition ${ }^{1} \mathrm{G}_{4} \rightarrow{ }^{3} \mathrm{H}_{5}$ (between 100 and $160 \mu$ s for $\operatorname{Pr}^{3+}$ concentrations from 150 to $900 \mathrm{ppm}$ ) is longer in the glass ceramics than that of the parent glass, increasing with increasing crystal fraction; and (3) Judd-Ofelt analysis shows that $\Omega_{2}$ decreases from 0.89 before the heat treatment to -0.88 in the glass ceramic, due to the higher ionic environment around the $\operatorname{Pr}^{3+}$ ions created by fluorine.

González Pérez et al. ${ }^{159}$ studied a similar glass composition, codoped with $\mathrm{Pr}^{3+} / \mathrm{Yb}^{3+}$. Comparing the JuddOfelt parameters $\Omega_{6}$ in the glass and glass ceramic, it can be estimated that around $80 \%$ of $\operatorname{Pr}^{3+}$ ions are located in the crystalline phase. $\mathrm{Pr}^{3+}$ emission at $1300 \mathrm{~nm}$ was detected under excitation at $980 \mathrm{~nm}$, according to the following mechanism

$$
\begin{aligned}
& \mathrm{Yb}^{3+}\left({ }^{2} \mathrm{~F}_{7 / 2}\right)+h v \rightarrow \mathrm{Yb}^{3+}\left({ }^{2} \mathrm{~F}_{5 / 2}\right)\left(\lambda^{\mathrm{ex}}=980 \mathrm{~nm}\right) \\
& \left.\mathrm{Yb}^{2} \mathrm{~F}_{5 / 2}\right)+\operatorname{Pr}^{3+}\left({ }^{1} \mathrm{G}_{4}\right) \rightarrow \\
& \operatorname{Pr}^{3+}\left({ }^{3} \mathrm{H}_{5}\right)+\mathrm{Yb}\left({ }^{2} \mathrm{~F}_{7 / 2}\right)(\text { energy transfer })
\end{aligned}
$$

The energy transfer probability from $\mathrm{Yb}^{3+}$ to $\mathrm{Pr}^{3+}$ increases with phonon density, such that the $\mathrm{Yb}^{3+}$ and $\mathrm{Pr}^{3+}$ radiative emission intensities decrease. The authors consider the possibility of phonon assisted cross-relaxation channels affecting the ${ }^{1} \mathrm{G}_{4}$ level of $\operatorname{Pr}^{3+}$. This work is a recent example of the open questions concerning the emission mechanisms and how external factors, such as temperature, provide useful information.

Tikhomirov et al. ${ }^{160}$ analysed $\mathrm{Er}^{3+}$ doped glass ceramics of composition $32 \mathrm{SiO}_{2}-9 \mathrm{AlO}_{1 \cdot 5}-31 \cdot 5 \mathrm{CdF}_{2}-$ $18 \cdot 5 \mathrm{PbF}_{2}-5 \cdot 5 \mathrm{ZnF}_{2}-3 \cdot 5 \mathrm{ErF}_{3}(\mathrm{~mol}-\%)$, by Raman spectroscopy, in which $\mathrm{PbF}_{2}$ crystals of average size $13 \mathrm{~nm}$ form. The existence of predominant $\mathrm{Q}^{2}$ units of $\mathrm{F}-\mathrm{Si}-\mathrm{O}$ tetrahedron as well as $\mathrm{Q}^{0}$ units in the interphase crystal glass was proved. In a similar work, $\mathrm{Er}^{3+}$ was substituted for $\mathrm{Tm}^{3+},{ }^{161}$ in which it was possible to quantify that $57 \%$ of $\mathrm{Tm}^{3+}$ is located in a crystalline matrix. The quantity of RE ions located in crystals can also be estimated from emission spectra, as reported by Boulard et al. ${ }^{162}$ in fluoride glass ceramics.

Apart from the infrared emission, Wang and Ohwaki's composition has been widely used to create materials producing visible emission through a UC mechanism. Takahashi et al. ${ }^{163}$ doped Wang-Ohwaki's composition with $\mathrm{Er}^{3+}$. After excitation at $800 \mathrm{~nm}$, intensive emission bands at 550 and $660 \mathrm{~nm}$ are 

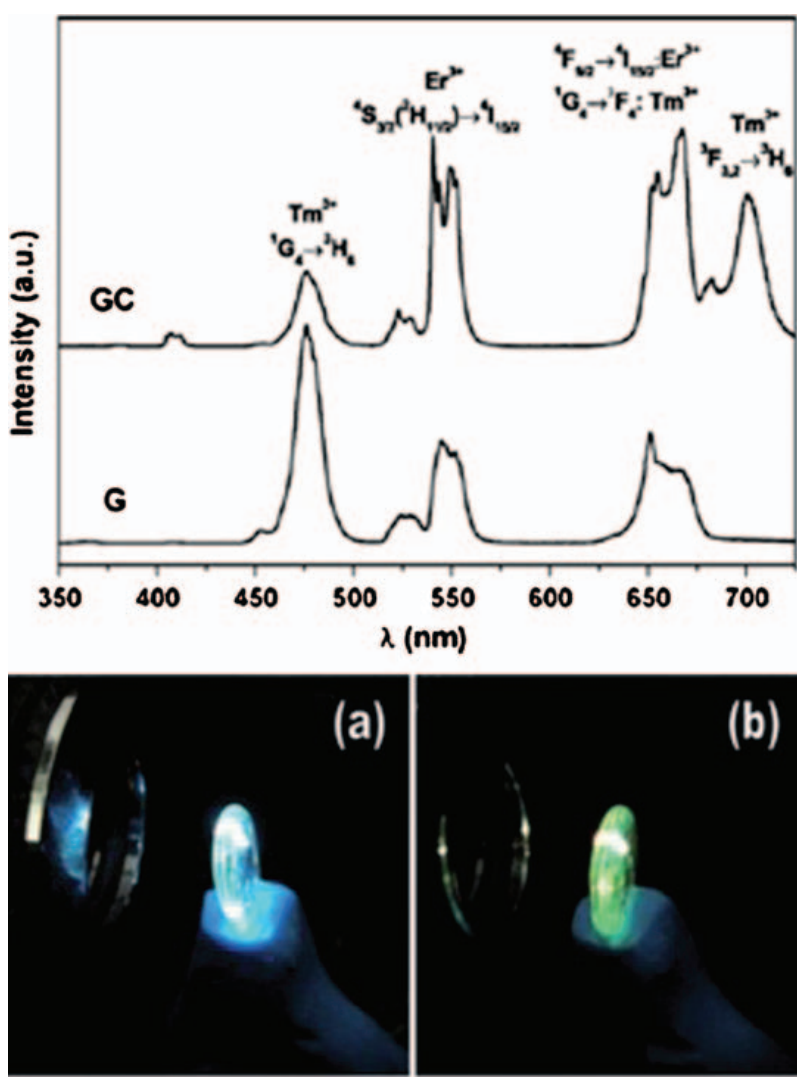

16

obtained. The $\mathrm{Er}^{3+}$ concentration dependence on UC intensity has been studied and a UC mechanism for both emission bands has been put forward.

Another variant of Wang-Ohwaki's glass ceramic is described by Kukkonen et al. ${ }^{164}$ starting from composition of $30 \mathrm{SiO}_{2}-15 \mathrm{Al}_{2} \mathrm{O}_{3}-29 \mathrm{CdF}_{2}-17 \mathrm{PbF}_{2}-3 \mathrm{YF}_{3}-5 \mathrm{ZnF}_{2}$ and $30 \mathrm{SiO}_{2}-15 \mathrm{Al}_{2} \mathrm{O}_{3}-29 \mathrm{CdF}_{2}-22 \mathrm{PbF}_{2}-4 \mathrm{ErF}_{3}-5 \mathrm{ZnF}_{2}$ (mol-\%). EDS spectra of the glass ceramics show an increase in the signal of $\mathrm{Er}^{3+}$ in the crystal phase and a subsequent decrease in the residual glass matrix.

A visible blue emission of $\mathrm{Tm}^{3+}$ has been widely studied due to its possible application in optical devices for high optical density storage, ${ }^{165}$ visible lasers, optical amplifiers, colour display, undersea optical communications, sensors, and in the field of medicine for biomedical diagnostics. ${ }^{166} \mathrm{Lahoz}$ et al. ${ }^{167}$ focused their studies on $\mathrm{Tm}^{3+} / \mathrm{Yb}^{3+}$ codoped glass ceramics of composition $30 \mathrm{SiO}_{2}-15 \mathrm{Al}_{2} \mathrm{O}_{3}-$ $29 \mathrm{CdF}_{2}-22 \mathrm{PbF}_{2}-(4-x-y) \mathrm{YF}_{3}-x \mathrm{TmF}_{3}-y \mathrm{YbF}_{3}$, with $x=0,0 \cdot 1$ and 1 , and $y=0$ and $2 \cdot 5$. This work shows the advantages of an oxide environment for the RE ion, instead of an ordered fluoride one, since an UC mechanism based on an energy transfer via phonons is suggested. The effect of the host lattice in this codoped system was studied by Sommerdijk. ${ }^{168}$ Absorption and excitation spectra of $0.1 \mathrm{Tm}^{3+}$ $2 \cdot 5 \mathrm{Yb}^{3+}(\mathrm{mol}-\%)$ codoped glass and glass ceramic are coincident, due to the fact that two $\mathrm{Tm}^{3+}$ ions are involved in the blue UC emission, so the glass ceramic excitation spectra is the result of the overlap between two absorption spectra, $2 \mathrm{Tm}\left({ }^{3} \mathrm{H}_{6}\right) \rightarrow 2 \mathrm{Tm}\left({ }^{3} \mathrm{H}_{4}\right)$. This has been demonstrated by the linear intensity dependence with pumping power of the bands at $475 \mathrm{~nm}$ $\left(\mathrm{Tm}^{3+}: \mathrm{G}_{4} \rightarrow{ }^{3} \mathrm{H}_{6}\right)$ and $975 \mathrm{~nm} \quad\left(\mathrm{Yb}^{3+}:{ }^{2} \mathrm{~F}_{5 / 2} \rightarrow{ }^{2} \mathrm{~F}_{7 / 2}\right)$, in which only one photon process takes place in the $\mathrm{Yb}^{3+}$ emission, while two photons are involved in the $\mathrm{Tm}^{3+}$ emission process. From the UC emission spectrum at $475 \mathrm{~nm}$, it is derived that $85 \% \mathrm{Tm}^{3+}$ ions are incorporated into the crystalline phase in the $1 \mathrm{Tm}^{3+}-2 \cdot 5 \mathrm{Yb}^{3+}(\mathrm{mol}-\%)$ glass ceramic, but it is concluded that the $\mathrm{Tm}^{3+}$ optically active centres are those which are not in the fluoride nanocrystals. This is in good agreement with a phonon assisted energy transfer between $\mathrm{Tm}^{3+}$ and $\mathrm{Yb}^{3+}$. However, this idea does not agree with that proposed by Zhang et al. ${ }^{169}$ in $\mathrm{Tm}^{3+} / \mathrm{Yb}^{3+}$ codoped glass and glass ceramic, in which the more intense UC emission in the glass ceramic, compared with that of the glass, is due to the crystalline surrounding of both ions, where the distances between them become shorter making the energy transfer processes easier. These results highlight the controversy concerning the UC mechanisms and the need for a complete structural characterisation of RE ions in glass ceramics.

Tikhomirov et al. ${ }^{170}$ and León-Luis et al. ${ }^{171}$ studied $\mathrm{Yb}^{3+} / \mathrm{Er}^{3+} / \mathrm{Tm}^{3+}$ codoped nanoglass ceramics. In the latter, the glass composition is $30 \mathrm{SiO}_{2}-15 \mathrm{AlO}_{1} \cdot 5-29 \mathrm{CdF}_{2}-$ $22 \mathrm{PbF}_{2}-1 \cdot 5 \mathrm{YF}_{3}-1 \cdot 5 \mathrm{YbF}_{3}-0 \cdot 5 \mathrm{ErF}_{3}-0 \cdot 5 \mathrm{TmF}_{3} \quad(\mathrm{~mol}-\%)$. A blue emission dominates the UC spectrum in the glass, while the green and red emissions are the most intense in the glass ceramic (after excitation at $980 \mathrm{~nm}$ ) leading to a tuneable material (Fig. 16).

Méndez-Ramos et al. ${ }^{172}$ studied a similar composition doped with $\mathrm{Nd}^{3+}$, in which the $\mathrm{Nd}^{3+}$ is added through a alcoholic nitrate solution to the other raw materials, forming after the evaporation, a very fine powder. This powder was heated in a furnace at $1050^{\circ} \mathrm{C}$ for $1 \mathrm{~h}$ and the melt was poured onto a stainless steel plate at room temperature. Transparent oxyfluoride glass ceramics were obtained by thermal treatment of the precursor glass. In comparison to the conventional melting method, UC efficiency is lower in glass ceramics obtained by the solution method, because the greater dispersion of ions in the solution makes the energy transfer processes more difficult.

Rodríguez et al. ${ }^{173}$ studied $\mathrm{Yb}^{3+} / \mathrm{Er}^{3+}$ codoped $\mathrm{PbF}_{2}$ glass ceramic obtained from a parent glass of composition $32 \mathrm{SiO}_{2}-9 \mathrm{AlO}_{1 \cdot 5}-31 \cdot 5 \mathrm{CdF}_{2}-18 \cdot 5 \mathrm{PbF}_{2}-5 \cdot 5$ $\mathrm{ZnF}_{2}-3 \cdot 5\left(\mathrm{Yb}^{3+} / \mathrm{Er}^{3+}\right) \mathrm{F}_{3}(\mathrm{~mol}-\%)$. An exhaustive analysis of the DC mechanisms is put forward, based on the emissions at 378, 450 and $486 \mathrm{~nm}$, developing blue to NIR photons. The DC efficiency reaches almost $200 \%$.

In contrast to studies of the UC processes, no comparative results between precursor glasses and glass ceramics are found in publications concerning DC. Nevertheless, it would be useful to study the DC efficiency depending on the RE ion environment.

We summarise this section by restating that Wang and Ohwaki's composition is a fundamental starting point for the design of new doped glass ceramics, providing infrared, visible and tunable emissions by changing the dopant ion for each desired wavelength. It is necessary to know the energy level diagram of the used dopant ions, as well as their population processes and location in the crystalline phase. Several questions are still open concerning the emission mechanisms of the employed RE ions. 
COLOUR FIGURE

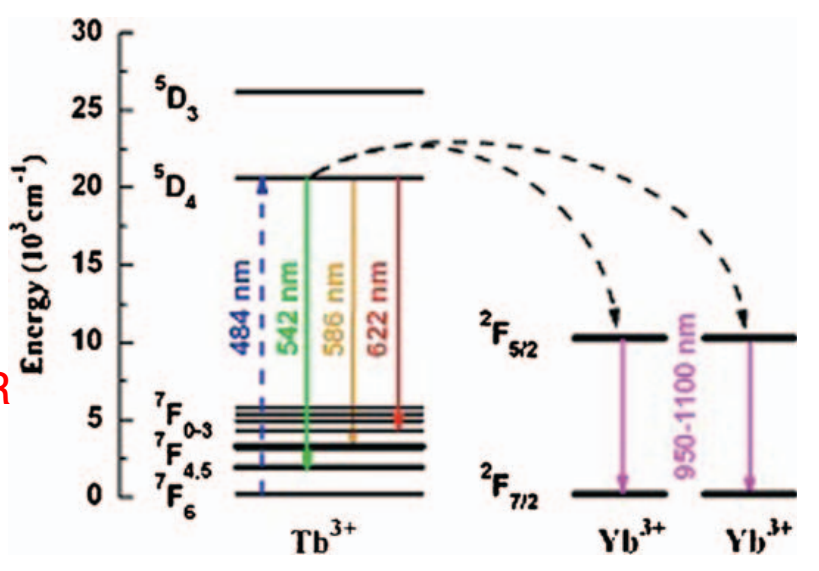

17

\section{Other compositions}

This section is focused on the crystallisation and luminescence properties of doped glass ceramics with crystalline phases which differ from that reported by Wang and Ohwaki. These compositions are classified by the precipitated crystalline phase: $\mathrm{CaF}_{2}, \mathrm{SrF}_{2}, \mathrm{BaF}_{2}$, $\mathrm{PbF}_{2}, \mathrm{YF}_{3}, \mathrm{LaF}_{3}, \mathrm{NaYF}_{4}$ and $\mathrm{NaLaF}_{4}$.

$R F_{2}(R=C a, S r, B a, P b)$

All these crystalline phases possess a cubic fluorite type structure (space group $\mathrm{Fm} \overline{3} \mathrm{~m}$ ), in which the $\mathrm{R}^{2+}$ cation is coordinated by eight fluoride anions and each $\mathrm{F}^{-}$ion is surrounded by four $\mathrm{R}^{2+}$ ions.

$\mathrm{CaF}_{2}$ exhibits a well known high transparency from 0.13 to $9.5 \mu \mathrm{m}$. The low phonon energy of $\mathrm{CaF}_{2}$, around $280 \mathrm{~cm}^{-1},{ }^{174}$ has given rise to the continuous development of glass ceramics containing this crystalline phase.

Huang et $a l .{ }^{175}$ developed $\mathrm{Yb}^{3+}$ and $\mathrm{Tb}^{3+}$ codoped oxyfluoride glass ceramics of composition $47 \cdot 4 \mathrm{SiO}_{2}-$ $19 \mathrm{Al}_{2} \mathrm{O}_{3}-28 \cdot 4 \mathrm{CaF}_{2}-2 \mathrm{TbF}_{3}-3 \cdot 2 \mathrm{YbF}_{3}$ (mol-\%). Emission bands at 381, 415 and $437 \mathrm{~nm}$ show a cubic dependence on the pump power at $974 \mathrm{~nm}$, while those at 490, 546, 588 and $622 \mathrm{~nm}$ exhibit quadratic dependence, indicating that three and two photons are involved respectively. Energy transfer processes occur between both ions. Moreover, the longer lifetime of the ${ }^{5} \mathrm{D}_{4}$ level in the glass ceramics compared with that of the glass increases the excited state absorption of this level, which is involved in the mechanism. Ye et al. ${ }^{176}$ also worked on $\mathrm{Yb}^{3+} / \mathrm{Tb}^{3+}$ codoped glass ceramics, of composition $60 \mathrm{SiO}_{2}$ $20 \mathrm{Al}_{2} \mathrm{O}_{3}-20 \mathrm{CaF}_{2}-0 \cdot 3 \mathrm{~Tb}^{3+}-x \mathrm{Yb}^{3+}(x=0,4,6,10,14$, $18,22,26$ and 30$)(\mathrm{mol}-\%)$. After excitation at $484 \mathrm{~nm}$, this material gives rise to an $\mathrm{Yb}^{3+}$ emission between 950 and $1100 \mathrm{~nm}$ (Fig. 17), which renders it suitable for DC applications. Recently, Lin et al. ${ }^{177}$ have reported $\mathrm{Tb}^{3+}$ / $\mathrm{Sm}^{3+}$ codoped oxyfluoride aluminosilicate $\mathrm{CaF}_{2}$ glass ceramics showing white light emission.

Chen et al. ${ }^{178,179}$ developed glasses and glass ceramics of composition $44 \cdot 5 \mathrm{SiO}_{2}-24 \cdot 8 \mathrm{Al}_{2} \mathrm{O}_{3}-5 \cdot 0 \mathrm{CaO}-9 \cdot 9 \mathrm{NaF}-$ $14 \cdot 8 \mathrm{CaF}_{2}(\mathrm{~mol}-\%)$ doped with different concentrations of $\mathrm{Er}^{3+}$. The work reported in Ref. 179 facilitates studies focused on $\mathrm{Er}^{3+}$ doped systems as it provides a compilation of spectroscopic measurements based on Judd-Ofelt theory, showing the radiative transition probabilities, the fluorescence branching ratios and the radiative decay times of the studied glass and glass ceramics. Green and red UC emissions are present in the glass ceramics after excitation at $980 \mathrm{~nm}$, whereas in the glasses, they were too weak and impossible to detect.
UC emission increases with $\mathrm{Er}^{3+}$ concentration up to 2 mol- $\%$, where after concentration quenching occurs. Zhou et al. ${ }^{180}$ obtained $\mathrm{Er}^{3+}$ doped glass ceramics containing $\mathrm{CaF}_{2}$ nanocrystals by the sol-gel method. A red UC emission takes place in the glass ceramics after excitation at $980 \mathrm{~nm}$.

$\mathrm{SrF}_{2}$ possesses phonon energy of $400 \mathrm{~cm}^{-1}$. Yu et al. ${ }^{181}$ reported an $\mathrm{Er}^{3+}$ doped $\mathrm{SrF}_{2}$ glass ceramic, which presents green and red UC emissions after excitation at $976 \mathrm{~nm}$, and DC in the same range after excitation at $379 \mathrm{~nm}$. $\mathrm{BaF}_{2}$ exhibits phonon energy of $346 \mathrm{~cm}^{-1}$. Qiao et al. ${ }^{182}$ reported glass ceramics of composition $60 \mathrm{SiO}_{2}-17 \mathrm{ZnF}_{2}-20 \mathrm{BaF}_{2}-3 \mathrm{ErF}_{3}(\mathrm{~mol}-\%)$ in which $\mathrm{BaF}_{2}$ is crystallised. Green and red UC luminescence is hardly observed in the glass upon excitation at $980 \mathrm{~nm}$, whereas in the obtained glass ceramics, it is very intense, increasing with treatment time at $650^{\circ} \mathrm{C}$. It is known that two phonons are involved in the mechanism from the UC intensity dependence on the pumping power. The suggested that mechanisms for both UC emissions in the glass ceramics include phonon decay processes, which is not expected for location of the $\mathrm{Er}^{3+}$ ions in a low phonon energy host such as $\mathrm{BaF}_{2}{ }^{183}$

$\mathrm{Yu}$ et al. ${ }^{184}$ reported a glass of composition $68 \mathrm{SiO}_{2}-$ $15 \mathrm{BaF}_{2}-13 \mathrm{~K}_{2} \mathrm{CO}_{3}-3 \mathrm{La}_{2} \mathrm{O}_{3}-1 \mathrm{Sb}_{2} \mathrm{O}_{3}-0 \cdot 5 \mathrm{ErF}_{3}(\mathrm{~mol}-\%)$. The fluorescence lifetime of the $\mathrm{Er}^{3+}$ transition ${ }^{4} \mathrm{I}_{13 / 2}$ $\rightarrow{ }^{4} \mathrm{I}_{15 / 2}$ in this material is remarkably longer, $13 \cdot 39 \mathrm{~ms}$, than that in other glasses and glass ceramics reported previously.

Li et al. ${ }^{185}$ developed glasses and glass ceramics of composition $52 \mathrm{SiO}_{2}-20 \mathrm{Al}_{2} \mathrm{O}_{3}-13 \mathrm{Na}_{2} \mathrm{O}-5 \mathrm{BaO}-10 \mathrm{BaF}_{2}$ (mol- $\%$ ), codoped with 1 mol- $\% \mathrm{Yb}_{2} \mathrm{O}_{3}, 0 \cdot 1$ mol- $\% \mathrm{Tm}_{2} \mathrm{O}_{3}$ and $0 \cdot 1$ mol- $\% \mathrm{Er}_{2} \mathrm{O}_{3}$. Blue, green and red UC emissions are found under excitation at $980 \mathrm{~nm}$, which are more intense in the glass ceramic material than in the corresponding glass, rendering this material suitable for generation of white light.

One of the few works which analyses the effect of RE ions on crystallisation is that of Rocha Barros et al. ${ }^{186}$ The composition of the glasses is $(100-x)\left(7 \cdot 52 \mathrm{Al}_{2} \mathrm{O}_{3}-\right.$ $\left.15 \cdot 04 \mathrm{~K}_{2} \mathrm{O}-1 \cdot 88 \mathrm{Na}_{2} \mathrm{O}-6 \mathrm{BaF}_{2}-69 \cdot 63 \mathrm{SiO}_{2}\right)-x \mathrm{BaO}(x=0$, $1 \cdot 5,3)($ mol- $\%)$, doped with $\mathrm{SmF}_{3}$ and $\mathrm{ErF}_{3}$. The undoped glass is homogenous, while the doped glasses present phase separation droplets. These regions seem to control further crystallisation mechanism. Transparent $\mathrm{Sm}^{3+}$ and $\mathrm{Er}^{3+}$ doped glass ceramics do not exhibit significant differences in the fluorescence emission spectra in comparison with undoped glass ceramics, indicating that most of the RE ions are distributed in the glass matrix, instead of in the crystalline phase.

Chen et al. ${ }^{187}$ reported glass ceramics of composition $x \mathrm{ErF}_{3}-5 \mathrm{BaF}_{2}-95 \mathrm{SiO}_{2}(x=0,0 \cdot 5,1 \cdot 0)(\mathrm{mol}-\%)$ obtained by the sol-gel method. Absorption spectra of the parent xerogel compared with the glass ceramics indicate a decrease in intensity of the hypersensitive transitions ${ }^{4} \mathrm{I}_{15 / 2}{ }^{4} \mathrm{G}_{11 / 2}$ and ${ }^{4} \mathrm{I}_{15 / 2}-{ }^{2} \mathrm{H}_{11 / 2}$ in the glass ceramics with respect to those in the precursor glass, indicating an alteration of the $\mathrm{Er}^{3+}$ environment from amorphous silica to crystalline fluoride on crystallisation.

$\mathrm{PbF}_{2}$ crystallisation in doped systems has also been reported in glass compositions different from those of Wang and Ohwaki. Duan et al. ${ }^{188}$ obtained white light from a glass of composition $40 \mathrm{SiO}_{2}-10 \mathrm{AlO}_{1 \cdot 5}-45 \mathrm{PbF}_{2}-$ $5 \mathrm{AlF}_{3}(\mathrm{~mol}-\%)$, doped with $\mathrm{Tm}^{3+}, \mathrm{Er}^{3+}$ and $\mathrm{Yb}^{3+}$, under excitation at $970 \mathrm{~nm}$. Zeng et al. ${ }^{189}$ based their 


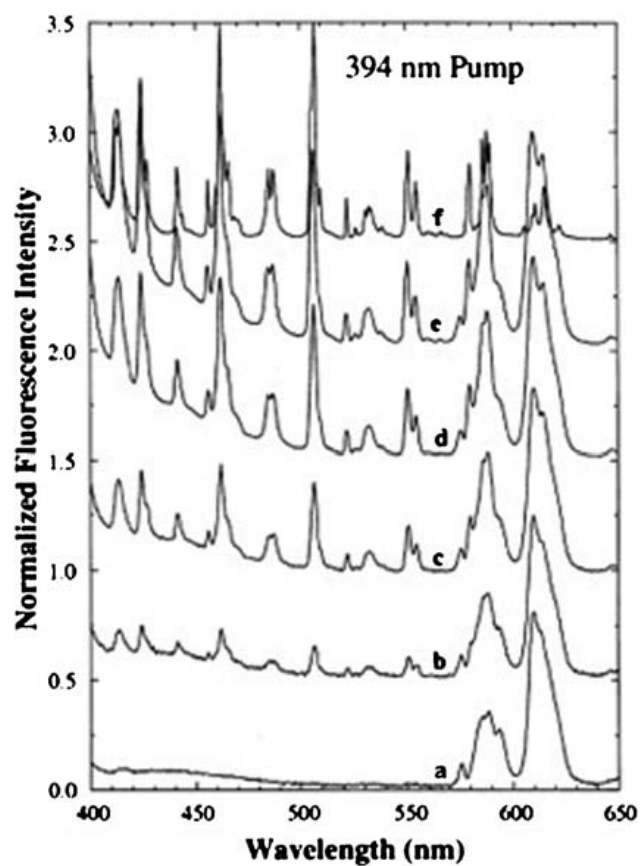

18

studies on $\mathrm{Er}^{3+}$ doped $\mathrm{PbF}_{2}$ glass ceramics of composition $50 \mathrm{SiO}_{2}-20 \mathrm{PbF}_{2}-30 \mathrm{PbO}-0 \cdot 5 \mathrm{Er}^{3+}(\mathrm{mol}-\%)$, where $\mathrm{Er}^{3+}$ ions act as nucleating agents. ${ }^{190,191}$ Several sources of $\mathrm{Er}^{3+}$ have been used including $\mathrm{Er}_{2} \mathrm{O}_{3}, \mathrm{ErOF}, \mathrm{ErF}_{3}$ and $\mathrm{ErCl}_{3}$. XRD peaks become sharper and more intense in the sequence $\mathrm{ErCl}_{3}<\mathrm{Er}_{2} \mathrm{O}_{3}<\mathrm{ErOF}<\mathrm{ErF}_{3}$, showing that $\mathrm{ErF}_{3}$ is the most suitable source.

$R F_{3}(R=Y, L a)$

At room temperature, $\mathrm{YF}_{3}$ presents orthorhombic symmetry with space group Pmma $\beta-\mathrm{YF}_{3}$. In this structure, the $\mathrm{Y}^{3+}$ ion lies in the centre of an irregular trigonal prism with six $\mathrm{F}^{-}$ions at the corners. Three more fluorine ions are symmetrically disposed in front of the prism lateral faces. These polyhedra form rings of six prisms, four of which share faces and the others edges.

$\mathrm{YF}_{3}$ crystals present phonon energy of $500 \mathrm{~cm}^{-1}$. $\mathrm{Nd}^{3+}$ fluorescence emissions in $\mathrm{YF}_{3}$ containing glass ceramics of composition $44 \mathrm{SiO}_{2}-28 \mathrm{Al}_{2} \mathrm{O}_{3}-17 \mathrm{NaF}-$ $11 \mathrm{YF}_{3}(\mathrm{~mol}-\%)$ are prime candidates for laser applications in the visible and ultraviolet range. ${ }^{192,193}$ Chen et al. ${ }^{194}$ reported $\mathrm{YF}_{3}$ glass ceramic codoped with $\mathrm{Ho}^{3+}$, $\mathrm{Tm}^{3+}$ and $\mathrm{Yb}^{3+}$, showing white light emission after excitation at $976 \mathrm{~nm}$. Chen et al. ${ }^{195}$ developed $\mathrm{Pr}^{3+} /$ $\mathrm{Yb}^{3+}$ codoped glass ceramics in the system $\mathrm{SiO}_{2}-\mathrm{Al}_{2} \mathrm{O}_{3}-$ $\mathrm{NaF}-\mathrm{YF}_{3}$, where $\beta-\mathrm{YF}_{3}$ crystallised. From excitation at $482 \mathrm{~nm}$ of the ${ }^{3} \mathrm{P}_{0}$ level of the $\operatorname{Pr}^{3+}$ ion, emissions in the red and in the NIR range are obtained.

$\mathrm{LaF}_{3}$ has a trigonal structure and crystallises in the tysonite structure $(\mathrm{P} \overline{3} \mathrm{c} 1)$ in which the site symmetry of $\mathrm{La}^{3+}$ is $\mathrm{C}_{2}$. Dejneka ${ }^{196}$ studied glass compositions in the range (50-70) $\mathrm{SiO}_{2}-(0-13) \mathrm{Na}_{2} \mathrm{O}-(20-32) \mathrm{Al}_{2} \mathrm{O}_{3}-(0-9) \mathrm{La}_{2} \mathrm{~F}_{6}$ (mol-\%) with several RE ions as dopants. Depending on the composition, different lanthanide fluoride phases crystallise. Under $394 \mathrm{~nm}$ excitation, fluorescence of EuF $_{3}$ containing glasses and glass ceramics showed bands at 576, 590 and $612 \mathrm{~nm}$, corresponding to ${ }^{5} \mathrm{D}_{0} \rightarrow{ }^{7} \mathrm{~F}_{0}$, ${ }^{5} \mathrm{D}_{0} \rightarrow{ }^{7} \mathrm{~F}_{1}$ and ${ }^{5} \mathrm{D}_{0} \rightarrow{ }^{7} \mathrm{~F}_{2}$ transitions respectively. The ratio ${ }^{5} \mathrm{D}_{0} \rightarrow{ }^{7} \mathrm{~F}_{1} /{ }^{5} \mathrm{D}_{0} \rightarrow{ }^{7} \mathrm{~F}_{2}$ increases with increasing temperature of heat treatment, indicating that the $\mathrm{Eu}^{3+}$ sites become

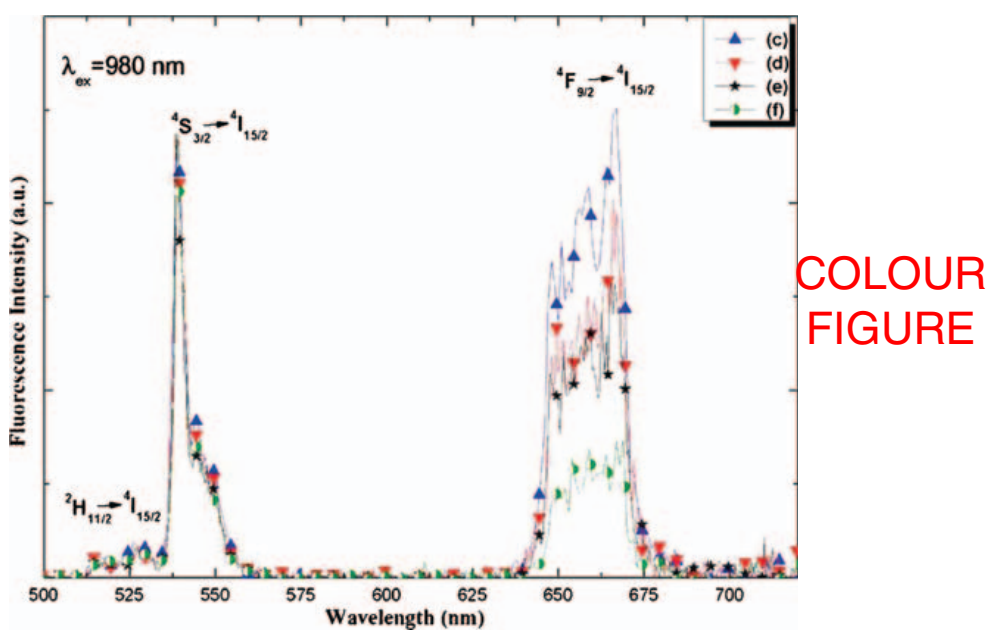

19

more symmetric (Fig. 18). Dejneka showed that the energy transfer between ${ }^{5} \mathrm{D}_{3},{ }^{5} \mathrm{D}_{2},{ }^{5} \mathrm{D}_{1}$ and ${ }^{5} \mathrm{D}_{0}$ takes place if the average distance between $\mathrm{Eu}^{3+}$ ions is shorter than $4 \mathrm{~nm}$, so the change in the emission bands is evidence of the location of some $\mathrm{Eu}^{3+}$ into fluoride crystals.

$\mathrm{Hu}$ et al. ${ }^{197}$ studied $\mathrm{Er}^{3+}$ doped glass ceramics with composition $41 \cdot 2 \mathrm{SiO}_{2}-29 \cdot 4 \mathrm{Al}_{2} \mathrm{O}_{3}-17 \cdot 6 \mathrm{Na}_{2} \mathrm{CO}_{3}-11 \cdot 8 \mathrm{La}$ $\mathrm{F}_{3}-x \mathrm{ErF}_{3}(x=0,0 \cdot 5,1,2,4,6)(\mathrm{mol}-\%)$. From the displacements of DSC peaks of samples with different $\mathrm{Er}^{3+}$ concentrations, the activation energy $E_{\mathrm{a}}$ and Avrami exponent $n$ were calculated by Chen's ${ }^{198}$ and Ozawa's ${ }^{199}$ equations. This work is one of the few which includes evidence of the effect of the doping agent on crystallisation. The crystal size changes with $\mathrm{ErF}_{3}$ concentration. The $a$ and $c$ lattice parameters of the precipitated $\mathrm{LaF}_{3}$ crystals also change with dopant concentration because of the incorporation of $\mathrm{Er}^{3+}$ into the crystalline lattice. Glass ceramics show great UC intensity in samples with higher crystallinity. The same composition has been doped with $\mathrm{Yb}^{3+},{ }^{200}$ which revealed that the linear emission intensity at $980 \mathrm{~nm}$ increases with $\mathrm{Yb}^{3+}$ concentration up to $4 \mathrm{~mol}-\%$, where quenching effects are present.

Ma et $a l .{ }^{201}$ also reported green and red UC emission in glasses of composition $41 \cdot 2 \mathrm{SiO}_{2}-29 \cdot 4 \mathrm{Al}_{2} \mathrm{O}_{3}-17 \cdot 6 \mathrm{Na}_{2} \mathrm{CO}_{3}-$ $11 \cdot 8 \mathrm{LaF}_{3}-1 \cdot 0 \mathrm{ErF}_{3}(\mathrm{~mol}-\%)$, in which $\mathrm{LaF}_{3}$ crystallised. Two main bands are associated with ${ }^{4} \mathrm{~F}_{9 / 2} \rightarrow{ }^{4} \mathrm{I}_{15 / 2}(660 \mathrm{~nm})$ and ${ }^{4} \mathrm{~S}_{3 / 2} \rightarrow{ }^{4} \mathrm{I}_{15 / 2}\left(540 \mathrm{~nm}\right.$ ) transitions of $\mathrm{Er}^{3+}$ (Fig. 19). A reduction of the emission intensity of the $660 \mathrm{~nm}$ band with the treatment time at $650^{\circ} \mathrm{C}$ is observed, since the population on the ${ }^{4} \mathrm{~F}_{9 / 2}$ level decreases with crystal growth. The authors proposed that interactions of the electronic states of RE ions in nanocrystals with the vibrational excitations of the surrounding glass medium and with the mixed vibrational modes of nanocrystallites, and the glass tend to be weaker with crystal size, so relaxation between ${ }^{4} \mathrm{~S}_{3 / 2}$ and ${ }^{4} \mathrm{~F}_{9 / 2}$ was more difficult, and the population on ${ }^{4} \mathrm{~F}_{9 / 2}$ decreased. Moreover, the ratio of the integrated intensity of the red $(660 \mathrm{~nm})$ and green emission $(540 \mathrm{~nm})$ changes when the heating time increases, so it is a suitable method for controlling both emissions.

Ye et al. ${ }^{202}$ reported $\mathrm{LaF}_{3}$ glass ceramics of composition $45 \mathrm{SiO}_{2}-12 \mathrm{Na}_{2} \mathrm{O}-23 \mathrm{Al}_{2} \mathrm{O}_{3}-20 \mathrm{LaF}_{3}-0 \cdot 5 \mathrm{Tm}^{3+}-x \mathrm{Yb}^{3+}(x=$ $0,4,8)(\mathrm{mol}-\%)$. After excitation at $468 \mathrm{~nm}$, infrared 


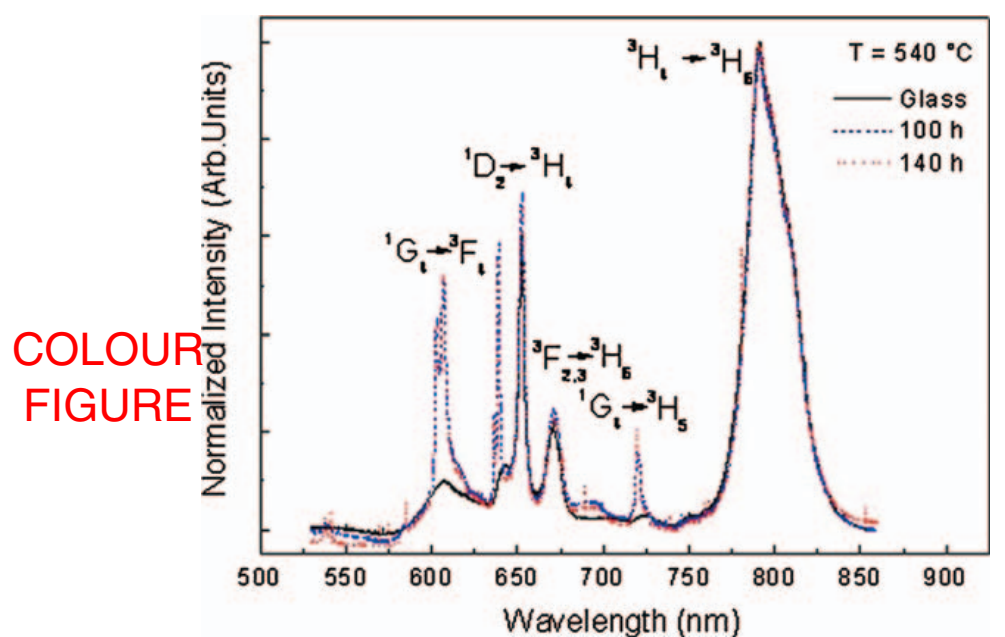

20

emission takes place through a cooperative energy transfer between a $\mathrm{Tm}^{3+}$ ion and two $\mathrm{Yb}^{3+}$ ions.

$\mathrm{LaF}_{3}$ glass ceramics prepared by sol-gel method have been developed, notably by the group of del Castillo and Yanes, ${ }^{31,32,203,204}$ who obtained doped glass ceramics by sol-gel, involving devitrification with an argon laser, which leads to the presence of crystals only in a small selected area.

\section{Mixed fluorides}

$\mathrm{NaYF}_{4}$ with a phonon energy of $360 \mathrm{~cm}^{-1}$, exists in two polymorphs at ambient temperature and pressure: the hexagonal $\mathrm{Na}_{1.5} \mathrm{Nd}_{1.5} \mathrm{~F}_{6}$ type structure and the cubic fluorite type structure, depending on the synthesis method. Liu et $a .^{205}$ studied the glass composition $40 \mathrm{SiO}_{2}-25 \mathrm{Al}_{2} \mathrm{O}_{3}-18 \mathrm{NaCO}_{3}-10 \mathrm{YF}_{3}-7 \mathrm{NaF}-x \mathrm{ErF}_{3} \quad(x=$ $0 \cdot 05,0 \cdot 2,0 \cdot 5,1 \cdot 0,2 \cdot 0)(\mathrm{mol}-\%)$, in which the main characteristic is the transition from cubic $\alpha-\mathrm{NaYF}_{4}$ to hexagonal $\beta-\mathrm{NaYF}_{4}$ when the temperature increases. $\beta$ $\mathrm{NaYF}_{4}$ seems to be more efficient in luminescence processes than the $\alpha$ structure, due to the multisite nature of the $\mathrm{Y}^{3+} / \mathrm{RE}^{3+}$ ions in the hexagonal $\mathrm{NaYF}_{4}$ crystal. $^{206,207}$ This kind of polymorphism was also reported for $\mathrm{NaGdF}_{4}: \mathrm{Eu}^{3+}$, obtained by hydrothermal synthesis. ${ }^{208}$ Yanes et al. ${ }^{209}$ also developed $\mathrm{NaYF}_{4}$ glass ceramics, codoped with $\mathrm{Er}^{3+} / \mathrm{Yb}^{3+}$, by the sol-gel method.

$\mathrm{NaLaF}_{4}$ crystallises in the space group $\mathrm{P} \overline{6}$ and has two $\mathrm{La}^{3+}$ sites, which are randomly occupied by the dopant ions. Both sites have tricapped trigonal prismatic coordination, one with $\mathrm{C}_{3 \mathrm{~h}}$ and the other with $\mathrm{C}_{1}$ site symmetry. The phonon energy is around $290 \mathrm{~cm}^{-1}$. de Pablos-Martin et al. ${ }^{210}$ reported an analysis of $\mathrm{NaLaF}_{4}$ nanocrystallisation within an aluminosilicate matrix doped with $\mathrm{Tm}^{3+}$. This work compares the undoped glass and glass ceramic in Ref. 96. with the $\mathrm{Tm}^{3+}$ doped analogues. Crystal sizes of the undoped glass ceramics are quite similar to those of $0.7 \% \mathrm{Tm}^{3+}$ doped glass ceramic treated at similar temperatures but for much longer times, indicating that the maximum crystal size is reached faster in the undoped glass ceramics. It is concluded, therefore, that the addition of $\mathrm{Tm}_{2} \mathrm{O}_{3}$ gives rise to a delay in the crystallisation process. The limitation in the crystal growth is related to the formation of a barrier diffusion layer around the crystals, as reported in Ref. 96. Emission spectra after excitation at $488 \mathrm{~nm}$ of the precursor glass and different glass ceramics are shown in Fig. 20. Additional and narrower bands appear in the glass ceramics in comparison with the parent glass, indicating the distribution of $\mathrm{Tm}^{3+}$ ions between both phases.

Zhao et al. ${ }^{211}$ reported $\mathrm{Ba}_{2} \mathrm{GdF}_{7}$ nanocrystals containing glass ceramics, codoped with $\mathrm{Eu}^{3+}, \mathrm{Tm}^{3+}$ and $\mathrm{Yb}^{3+}$. This material shows white light emission under excitation at $392 \mathrm{~nm}$.

\section{Possible applications of doped nanocrystalline glass ceramics}

Two main applications of oxyfluoride nanoglass ceramics have been reported in this review:

(i) UC and white light generation waveguides

(ii) DC materials, especially useful for the improvement of solar cells.

\section{UC materials Waveguides}

The number of works studying the production of waveguides from glass ceramic materials is very low, ${ }^{212,213}$ especially those focused on oxyfluoride systems.

Since the concept of internal reflection was developed in the nineteenth century, light guiding has advanced to a point where it has revolutionised information technology. Nowadays, it is required for medical applications and the transmission of information over long distances, including telephony, Internet traffic, long high speed local area networks, cable TV, etc. ${ }^{214,215}$ The incorporation of RE ions into waveguides created a significant interest in finding materials which cover the broad available bandwidth of the spectra required for optical communications. Nowadays, $\mathrm{Er}^{3+}$ and $\mathrm{Tm}^{3+}$ doped fibres are useful in the third window of the spectra, since the emission occurs at $1.54 \mu \mathrm{m}$ for $\mathrm{Er}^{3+}$ and between 1.450 and $1.480 \mu \mathrm{m}$ for $\mathrm{Tm}^{3+}$, while $\mathrm{Pr}^{3+}$ doped fibres operate in the second window, at $1.3 \mu \mathrm{m}$. Attenuation along the waveguide is one of the main factors impacting on the design of the material. Current efforts are focused on finding materials with propagation losses lower than $0 \cdot 1 \mathrm{~dB} \mathrm{~cm}^{-1}$. A major improvement in this area was the achievement of efficient pump beam propagation in the core of the fibre, and the subsequent gain, directly amplifying the output optical signal, ${ }^{216}$ and avoiding the use of intermediate electronic devices. The largely suppressed multiphonon transitions in fluoride environments are very important for the fabrication of fibre lasers and amplifiers; thus oxyfluoride glass ceramics are very good candidates for these devices.

In 1969, Bell Laboratories developed the first optical integrated circuit, in which various components are interconnected with optical waveguides on a substrate, referred to as an integrated optical device (IODs). The advantages of using IODs compared with a long doped fibre are the lower cost and the decrease of interactions between RE ions. Jacquier et al. $^{217}$ has reviewed the main properties of RE doped fibres and IODs.

The ion exchange technique ${ }^{218,219}$ (Fig. 21) is used to obtain waveguiding regions by exchanging certain cations from the glass for cations from a salt melt solution. ${ }^{220}$ Changes in polarisability and molar volume result in zones of higher refractive index, where the light is confined. Structural changes produced by ion exchange process are detailed by Brandenburg ${ }^{221}$ and 


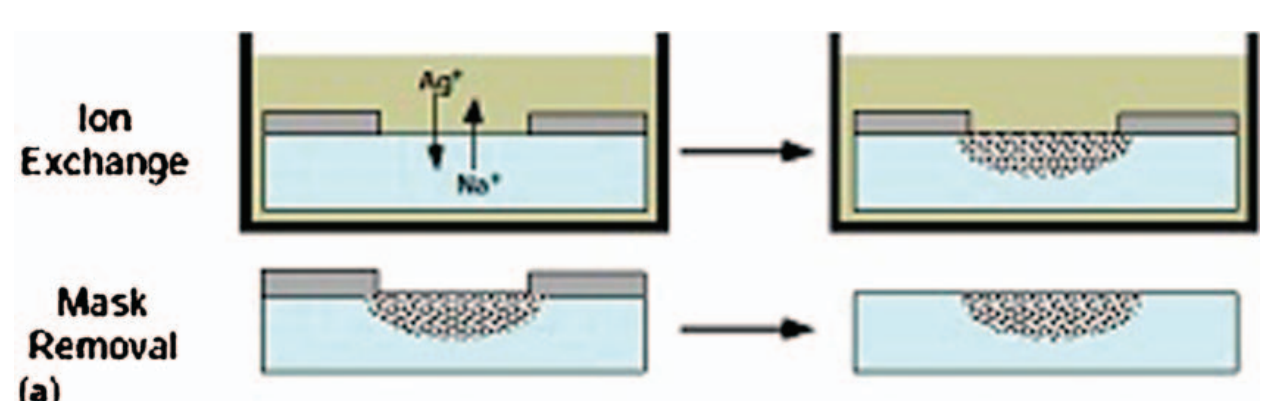

(a)

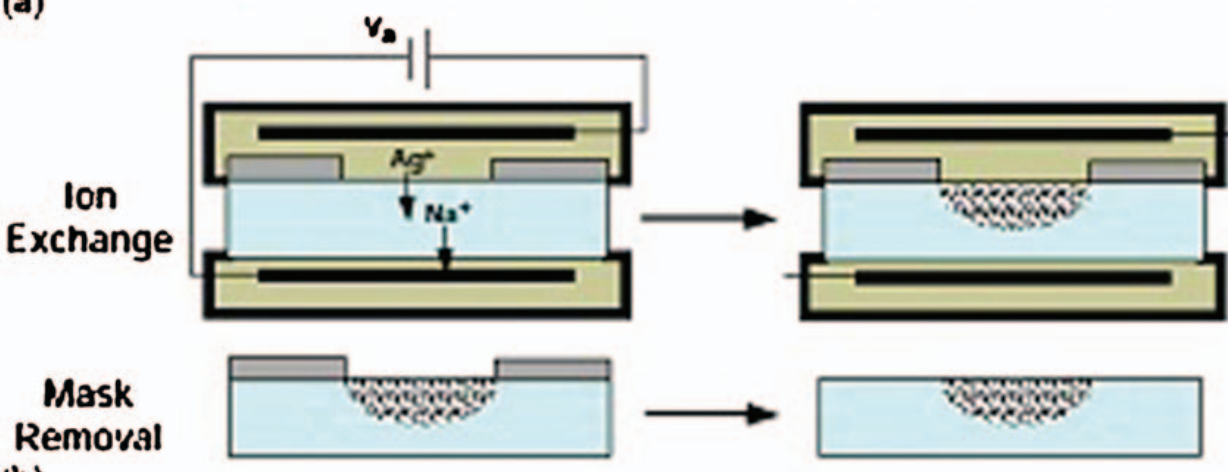

(b)

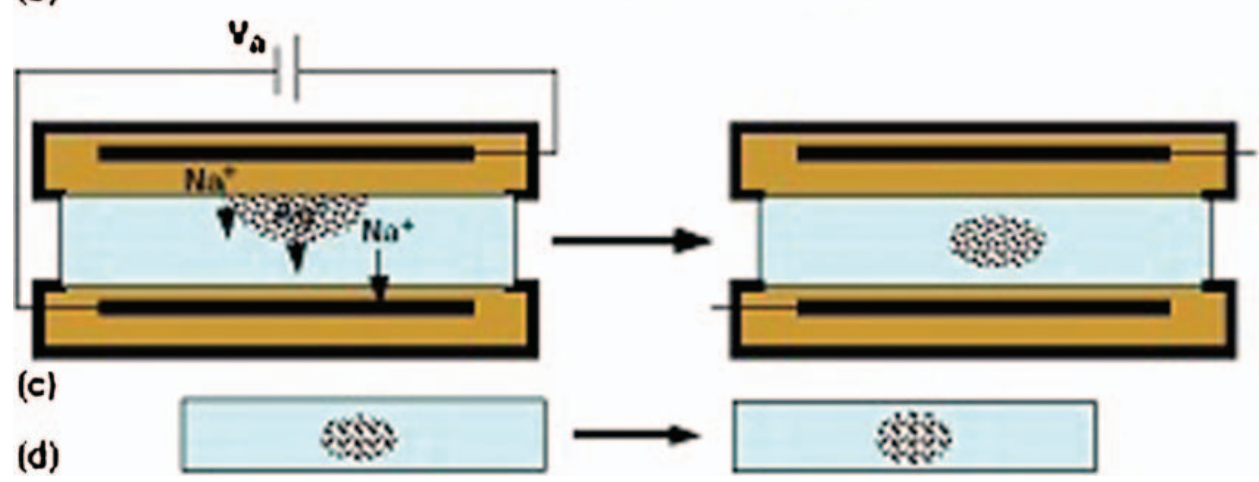

later Tyagi and Varshneya ${ }^{222}$ Silver-sodium exchange has been particularly well studied, ${ }^{223}$ especially the formation of Ag clusters, which give the characteristic yellow colour in the glass samples. ${ }^{224} \mathrm{Ag}$ particles are detectable by absorption measurements, showing a plasmon resonance at around $400 \mathrm{~nm}$. Portales et al. ${ }^{225}$ reported important results showing an enhancement of the $1.5 \mu \mathrm{m}$ luminescence in annealed $\mathrm{Er}^{3+}$ doped $\mathrm{Ag}$ exchanged silicate glasses when the excitation wavelength is similar to that of the Ag plasmon absorption band. Righini et $a l^{226}$ and Berneschi et al. $^{227}$ have detailed similar effects.

The number of optical modes is defined by changing the ion concentration of the salt melt solution and the temperature and time of the ion exchange process. Typically, for amplification purposes in the infrared region, single mode waveguides are used, while for UC materials, in which high energy photons are produced, several modes are needed.

In principle, the use of glass ceramics in this field could be a disadvantage, since the crystals would contribute to light scattering. ${ }^{228}$ On the other hand, when electrical control of light propagation or high nonlinearity is necessary in optical waveguides, the presence of crystals in a glassy matrix is favourable. Thus, an exhaustive control of the crystallisation process must be developed in order to obtain ultra transparent glass ceramics with a homogenous size distribution of nanocrystals with particle size of only a few nanometres in order to avoid light scattering. Usually, work focused on the preparation of glass ceramic waveguides starts from the parent glasses and employs thermal treatment during ion exchange to produce the glass ceramics. ${ }^{229,230}$ To our knowledge, not many syntheses start directly from the glass ceramic materials.

\section{Photovoltaics}

Richards ${ }^{231}$ described the advantages of applying UC to photovoltaics for the following reasons: (1) visible light is achieved, with higher energy than that of the band gap $E_{\mathrm{g}}$ of Si solar cells; (2) an UC layer can be placed upon the rear of a bifacial solar cell without disturbing the performance of the device for incident photons with energy $E>E_{\mathrm{g}}$; and (3) with a reflector placed behind the UC layer, no luminescence can escape out of the rear. On the other hand, the major disadvantage of UC is that it is a non-linear optical process. Thus, for the minimum two-step UC process, the intensity of UC light $I$ is related to the incident light intensity $I_{0}$ by $I / I_{0}{ }^{2}$, while for a three-step UC process, it is $I / I_{0}{ }^{3}$.

\section{DC materials}

Zhang and Huang ${ }^{116}$ reviewed NIR quantum cutting glass-ceramics containing $\mathrm{BaF}_{2}, \mathrm{CaF}_{2}, \mathrm{TbF}_{3}, \mathrm{LaF}_{3}$ and $\mathrm{YF}_{3}$ nanocrystals. This work states that there are still many areas to be improved, highlighting the need for a 
better understanding of material properties, fabrication processes and DC mechanisms. They concluded that a great number of newer concepts and novel materials are still in the research stage, which will lead to much higher efficiency and lower costs in the coming decades.

In contrast to RE doped glasses and crystalline phases, ${ }^{112}$ RE doped glass ceramic materials are still not near to market in optics or photovoltaic applications. However, intensive research is currently focused on finding the best experimental conditions in order to achieve a higher crystalline fraction, maintaining the transparency, locating the majority of the RE ions in the crystalline phase, minimising the propagation losses and improving the optical emission rates. There exist a great number of possibilities in these fields, since several crystalline phases and RE ions are involved, where combination could be of interest. Richards ${ }^{232}$ reported the requirements and limitations of luminescent materials for in-lighting, display and photovoltaic applications. The main challenges are: (1) higher stability, to avoid the formation of defects (fluorides are known to be damaged by vacuum ultraviolet radiation, reducing the efficiency of the luminescence); (2) higher emission lifetime, to increase the efficiency of luminescent processes; (3) the high price of RE minerals and the necessary purification process for lanthanides remains a barrier; and (4) reflection of the host material must be minimised in order to focus the light into the excited levels of the RE ions.

\section{Conclusions}

The general principles of nanocrystallisation in glasses have been reviewed with especial attention paid to the crystallisation of fluoride phases. Two different trends, which attempt to analyse the nanocrystallisation mechanisms, have been discerned. The base outlined by Stoch and Sroda et al. should be considered in the first stages of crystallisation, since they are based on theoretical aspects, such as crystallisation enthalpies, bond ionicities, heat capacities and thermal stability indices, allowing the crystallisation mechanism to be predicted. However, to complete these studies, a deeper knowledge of the structure and composition of the interphases formed between glass matrix and crystal, their evolution during crystallisation and the percolation theory, as suggested by Rüssel et al. is necessary. Both approaches represent the foundations for a better understanding of crystallisation phenomena in nonisochemical systems in general.

Nanocrystallisation has been successfully developed and transferred to the market for telescope mirrors, cook panels and fireplaces. However, the most relevant and recent publications concern optically active materials, in which the advantages of using RE doped oxyfluoride glass ceramics are put forward. Since Wang and Ohwaki reported their glass ceramics in 1993, changes in the original composition with different crystalline phases and dopant ions have been investigated. $\mathrm{LaF}_{3}$ is an extensively studied fluoride, although recent investigations are focused on heavy fluorides, like $\mathrm{PbF}_{2}$, and double fluorides, especially $\mathrm{NaYF}_{4}$. More information about the influence of the addition of RE ions on crystallisation is needed by comparing doped and undoped systems.
Oxyfluoride glass ceramics offer an immense range of possibilities, for not only various compositions, crystalline phases and dopanting parameters, but also the final shape of the material. These include waveguides for IODs produced by melting, coatings and thin films made by sol-gel, nanoparticles, fibres, spherical devices, etc. From our point of view, finding the best material requires improvement of several factors: crystallisation of the appropriate fluoride crystal and doping with the ideal RE ion, a high crystalline fraction and maximum incorporation of the $\mathrm{RE}$ ion into the crystalline structure, costs of the raw materials, etc. These could be the reasons for the delay in the application of such materials in commercial devices, compared with the current glassy and crystalline analogues. This review has highlighted the importance of a complete understanding of the mechanisms of nucleation and crystallisation of fluoride nanocrystals in glasses.

The mechanisms that control the optical emissions have been reported, especially different kinds of energy transfer processes between excited states, giving rise to up- and down-conversion phenomena.

The perspectives of these materials represent a promising future for a great number of applications, especially in optics and photovoltaics.

\section{Acknowledgements}

The authors acknowledge the financial support of Project INTERCONY, contract no. NMP4-CT-2006033200 from the Sixth Framework of the European Union, as well as all members of the project for helpful discussions, the CSIC Incorporation Intramural Project 2007 60I002, and the CiCyt project MAT 2010-20459. A. de Pablos-Martín is grateful to CSIC for a JAE contract.

\section{References}

1. Y. Wang and J. Ohwaki: Appl. Phys. Lett., 1993, 63, 3268.

2. G. Tammann: 'Der Glaszustand'; 1933, Leipzig, L. Voss.

3. A. K. Jackson: Ind. Eng. Chem., 1965, 54, (12), 29-32.

4. R. L. Thakur, K. Takijawa, T. Sakaino and T. Moriya: Glass Ceram. Res. Inst. Bull., 1964, 1, 1-22.

5. D. Turnbull and M. A Cohen: 'Crystallisation kinetics and glass formation', in 'Modern aspects of the vitreous state', (ed. J. D. Mackenzie), 1; 1960, Washington, DC, Butterworth Inc.

6. D. R. Uhlmann and B Chalmers: Ind. Eng. Chem., 1965, 57, (9), 19-31.

7. J. J. Hammel: 'Nucleation in glass. A review', in 'Advances in nucleation and crystallisation in glasses'; 1971, Columbus, $\mathrm{OH}$, American Ceramic Society.

8. S. Toschev and I. Gutzow: Phys. Status Solidi, 1967, 21, 683.

9. B. Hinz: Silikattechnik, 1960, 11, (10), 455-459.

10. H. R. Lillie: Glass Technol., 1960, 1, (3), 115-120.

11. O. Robredo: Verres Réfract., 1962, 16, (4), 225-230; (5), 282-289.

12. M. Tashiro: Glass Ind., 1966, 47, 366-373, 428-435.

13. McMillan: 'Glass-ceramics', 1964, London/New York, Academic Press.

14. K. D. Kim and S. H. Lee: J. Non-Cryst. Solids, 2004, 336, 195201.

15. H. E. Kissinger: J. Res. Natl Bur. Stand., 1956, 57, 217-221.

16. Y. Senol, T. Osman and Ozkan: Ceram. Int., 1996, 22, 477-481.

17. M. Poulain: J. Non-Cryst. Solids, 1992, 140, 1-9.

18. M. Avrami: J. Chem. Phys., 1939, 7, 1103.

19. M. Avrami: J. Chem. Phys., 1940, 8, 212.

20. M. Avrami: J. Chem. Phys., 1941, 9, 177.

21. W. A. Johnson and R. F. Mehl: Trans. Am. Inst. Miner. Metall. Eng., 1939, 135, 416.

22. B. N. Kolmogorov: Izv. Akad. Nauk. URSS Ser. Mater., 1937, 3, 355 . 
23. L. A. Pérez-Maqueda, J. M. Crudo and J. Malek: J. Non-Cryst. Solids, 2003, 320, 84-91.

24. S. D. Stookey: Res. Manage., 1958, 1, (3), 155-163.

25. S. D. Stookey: 'Catalyzed crystallisation of glass, in theory and practice', Ind. Eng. Chem., 1959, 1, 805.

26. S. Bhattacharyya, Th. Höche, K. Hahn and P. A. van Aken: J. Non-Cryst. Solids, 2009, 355, (6), 393-396.

27. W. Vogel: 'Glass chemistry', 2nd edn, 291; 1994, Berlin, SpringerVerlag.

28. B. Li, Z. X. Yue, J. Zhou, Z. L. Gui and L. T. Li: Mater. Lett., 2002, 54, 25-29.

29. S. Cai, W. J. Zhang, G. H. Xu, J. Y. Li, D. M. Wang and W. Jiang: J. Non-Cryst. Solids, 2009, 355, 273-279.

30. Q.-Z. Chen, Y. Li, L.-Y. Jin, J. M. W. Quinn and P. A. Komesaroff: Acta Biomater., 2010, 6, 4143-4153.

31. J. J. Velázquez, A. C. Yanes, J. del Castillo, J. Méndez-Ramos and V. D. Rodríguez: J. Non-Cryst. Solids, 2010, 356, 1349-1353.

32. A. C. Yanes, J. J. Velázquez, J. del Castillo, J. Méndez Ramos and V. D. Rodríguez: J. Sol-Gel Sci. Technnol., 2009, 51, 4-9.

33. L. Stoch: J. Therm. Anal. Calorim., 1998, 54, 9.

34. M. Sroda, I. Waclawska, L. Stoch and M. Reben: J. Therm. Anal. Calorim., 2004, 77, 193-200.

35. I. Avramov, R. Keding and C. Rüssel: J. Non-Cryst. Solids, 2000, 272, 147-153

36. I. Avramov, R. Keding, C. Rüssel and R. Kranold: J. Non-Cryst. Solids, 2000, 278, 13-18.

37. R. P. F. de Almeida, C. Bocker and C. Rüssel: Chem. Mater., 2008, 20, 5916-5921.

38. I. Avramov, R. Keding and C. Rüssel: Glass. Sci. Technol., 2000, 73C1, 138-145.

39. R. G. Hill, M. D. O’Donnell, R. V. Law, N. Karpukhina, B. Cochrane and D. U. Tulyaganov: J. Non-Cryst. Solids, 2010, 356, 2935-2941

40. C. Rüssel: Chem. Mater., 2005, 17, 5843-5847.

41. I. Avramov, R. Keding, C. Rüssel and R. Kranold: J. Non-Cryst. Solids, 2000, 278, 13-18.

42. I. Avramov, A. Milchev and P. Argyrakis: Phys. Rev. E, 1993, 47E, (4), 2303.

43. N. Tsakiris, P. Argyrakis and I. Avramov: Phys. Rev. E, 2010, 81E, 022101.

44. N. Tsakiris, P. Argyrakis, I. Avramov, C. Bocker and C. Rüssel: Europhys. Lett., 2010, 89, 18004.

45. M. J. Pascual, C. Lara and A. Durán: Eur. J. Glass Sci. Technol. $B, 2006,47 \mathrm{~B},(5), 572-581$.

46. I. W. Donald: J. Non-Cryst. Solids, 2004, 345, 120-126.

47. M. J. Pascual, C. Lara and A. Duran: J. Glass Sci. Technol. B, 2006, 47B, (5), 572-581.

48. A. Stamboulis, R. G. Hill and R. V. Law: J. Non-Cryst. Solids, 2005, 351, 3289-3295.

49. T. J. Kiczenski and J. F. Stebbins: J. Non-Cryst. Solids, 2002, 306, $160-168$.

50. W. A. Pisarski, J. Pisarska, M. Maczka, R. Lisiecki, Ł. Grobelny, T. Goryczka, G. Dominiak-Dzik and W. Ryba-Romanowski: Spectrochim. Acta A, 2011, to be published.

51. C. Bessada, A. Rakhmatullin, A. L. Rollet and D. Zanghi: J. Fluor. Chem., 2009, 109, 45-52.

52. D. Furniss, E. A. Harris and D. B. Hollis: J. Phys. C: Solid State Phys., 1987, 20C, L147-L150.

53. B. Sreedhar, P. Indira and A. K. Bhatnagar: 'EPR spectra of transition metal and rare-earth ions in lithium fluoroborate glasses', Proc. AIP Conf.: 'Ordering disorder: prospect and retrospect in condensed matter physics', Hyderabad, India, December-January1992, AIP, Vol. 286, 258-260.

54. M. Takahashi, R. Kanno and Y. Kawamoto: J. Phys. Chem., 1996, 100, (26), 11193-11197.

55. M. J. Weber: Phys. Rev., 1967, 157, (2), 262-272.

56. B. R. Judd: Phys. Rev., 1962, 127, 750-761.

57. G. S. Ofelt: J. Chem. Phys., 1962, 37, 511-520.

58. R. Moncorgé: in 'Spectroscopic properties of rare earths in optical materials', Springer Series in Materials Science, Vol. 83, 320-378; 2005, Berlin, Springer.

59. M. C. Gonçalves, L. F. Santos and R. M. Almeida: C. R. Chim., 2002, 5, 12, 845-854.

60. M. M. Lezhnina, H. Kaetker and U. H. Kynast: Opt. Mater., 2007, 30, 264-272.

61. F. Lahoz, I. R. Martín, U. R. Rodríguez-Mendoza, I. Iparraguirre, J. Azkargorta, A. Mendioroz, R. Balda, J. Fernández and V. Lavín: Opt. Mater., 2005, 27, 1762-1770.

62. A. Edgar, G. V. M. Williams and J. Hamelin: Curr. Appl. Phys., 2006, 6, 355-358.
63. T. Döhring, R. Jedamzik, V. Wittmer and A. Thomas: Proc. SPIE, 2004, 5494, 340-349.

64. T. Döhring, R. Jedamzik and P. Hartmann: Proc. SPIE, 2007, 6689.

65. T. Döhring, R. Jedamzik, A. Thomas and H. Morian: Proc. SPIE, 2003, 4851, 647-655.

66. G. H. Beall and D. A. Duke: J. Mater. Sci., 1969, 4, 340-352.

67. G. H. Beall and L. R. Pinckney: J. Am. Ceram. Soc., 1999, 82, 516.

68. P. Riello, P. Canton, N. Comelato, S. Polizzi, M. Verità, G. Fagherazzi, H. Hofmeister and S. Hopfe: J. Non-Cryst. Solids, 2001, 288, 127-139.

69. X. Z. Guo, H. Yang, M. Cao, C. Han and F. F. Song: Trans. Nonferr. Met. Soc. China, 2006, 16, 593-597.

70. R. Wurth, F. Muñoz, M. Müller and C. Rüssel: Mater. Chem. Phys., 2009, 116, 433-437.

71. S. Bhattacharyya, T. Höche, J. R. Jinschek, I. Avramov, R. Wurth, M. Müller and C. Rüssel: Cryst. Growth Des., 2010, 10, 379-385.

72. F. Gabel, W. Kiefer, G. Müller, W. Pannhorst and R. Sprengard: Glastech. Ber. Glass Sci. Technol., 2000, 73, (C1), 337.

73. R. Sprengard, U. Fotheringham, W. Pannhorst and K. Binder: http://www.schott.com/rd/german/download/zusammensetzung12. pdf

74. K. Soga, W. Wang, R. E. Riman, J. B. Brown and K. R. Mikeska: J. Appl. Phys., 2003, 93, 2946.

75. D. W. Hewak, R. S. Deol, J. Wang, G. Wylangowski, J. A. Mederios Neto, B. N. Samson, R. I. Laming, W. S. Brocklesby, D. N. Payne, A. Jha, M. Poulain, S. Otero, S. Surinach and M. D. Baro: Electron. Lett., 1993, 29, 237.

76. E. R. Taylor, L. N. Ng, N. P. Sessions and H. Buerger: J. Appl. Phys., 2002, 92, 112

77. Joint Committee on Powder Diffraction Standards (JCPDS) file 8-461 $\mathrm{LaF}_{3}$

78. M. Sroda and Cz. Paluszkiewicz: Vib. Spectrosc., 2008, 48, 246250 .

79. M. Sroda, Cz. Paluszkiewicz, M. Reben and B. Handke: J. Mol. Struct., 2005, 744-747, 647-651.

80. M. Reben, I. Waclawska, Cz. Paluszkiewicz and M. Sroda: J. Therm. Anal. Calorim., 2007, 88, (1), 285-289.

81. N. Hémono, G. Pierre, F. Muñoz, A. de Pablos-Martín, M. J. Pascual and A. Durán: J. Eur. Ceram. Soc., 2009, 29, 2915-2920.

82. S. Bhattacharyya, Th. Höche, N. Hemono, M. J. Pascual and P. A. van Aken: J. Cryst. Growth, 2009, 311, 4350-4355.

83. F. Muñoz, A. de Pablos-Martín, N. Hémono, M. J. Pascual, A. Durán, L. Delevoye and L. Montagne: J. Non-Cryst. Solids, 2011, 357, 1463-1468.

84. R. E. Youngman and M. J. Dejneka: J. Am. Ceram. Soc., 2002, 85, 1077-1082

85. T. J. Kiczenski, L.-S. Du and J. F. Stebbins: J. Non Cryst. Solids, 2004, 337, 142-149.

86. J. F. Stebbins and Q. Zeng: J. Non Cryst. Solids, 2000, 262, 1-5.

87. K. Ritter, S. Gerlach and C. Rüssel: J. Non-Cryst. Solids, 2010, 356, 3090-3094.

88. C. Bocker and C. Rüssel: J. Eur. Ceram. Soc., 2009, 29, 12211225 .

89. C. Bocker, S. Bhattacharyya, T. Höche and C. Rüssel: Act. Mater., 2009, 57, 5956-5963.

90. S. Bhattacharyya, C. Bocker, T. Heil, J. R. Jinschek, T. Höche, C. Rüssel and H. Kohl: Nano Lett., 2009, 9, (6), 2493-2496.

91. C. Bocker, F. Muñoz, A. Durán and C. Rüssel: J. Solid State Chem., 2011, 184, (2), 405-410.

92. C. Bocker, I. Avramov and C. Rüssel: Chem. Phys., 2010, 369, 96 100.

93. C. Bocker, I. Avramov and C. Rüssel: Scr. Mater., 2010, 62, 814 817.

94. F. Liu, Y. Wang, D. Chen and Y. Yu: Mater. Sci. Eng. B, 2007, B136, 106-110.

95. M. Sroda: J. Therm. Anal. Calorim., 2009, 97, 239-243.

96. A. de Pablos-Martín, G. C. Mather, F. Muñoz, S. Bhattacharyya, T. Höche, J. R. Jinschek, T. Heil, A. Durán and M. J. Pascual: J. Non-Cryst. Solids, 2010, 356, 3071-3079.

97. G. Liu and B. Jacquier: in 'Spectroscopic properties of rare earths in optical materials', Springer Series in Materials Science, Vol. 83; 2005, Beijing, Springer.

98. J. F. Suyver, A. Aebischer, D. Biner, P. Gerner, J. Grimm, S. Heer, K. W. Krämer, C. Reinhard and H. U. Güdel: Opt. Mater., 2005, 27, 1111-1130.

99. Y. Cong, B. Li, B. Lei, X. Wang, C. Liu, J. Liu and W. Li: J. Lumin., 2008, 128, 105-109. 
100. P. A. Azeem, M. Kalidasan, K. Rama Gopal and R. R. Reddy: J. Alloys Compd, 2009, 474, 536-540.

101. B. C. Jamalaiah, J. Suresh Kumar, A. Mohan Babu, L. Rama Moorthy: J. Alloys Compd, 2009, 478, 63-67.

102. Z. Lu, J. Wang, Y. Tang and Y. Li: J. Solid State Chem., 2004, 177, 3075-3079.

103. Z. Wang, M. Li, Ch. Wang, J. Chang, H. Shi and J. Lin: J. Rare Earths, 2009, 27, (1), 33.

104. X. Qiao, Q. Luo, X. Fan and M. Wang: J. Rare Earth, 2008, 26 , (6), 883 .

105. P. Babu and C. K. Jayasankar: Physica B, 2000, 279B, 262-281.

106. R. Reisfeld, E. Zigansky and M. Gaft: Mol. Phys., 2004, 102, 1319-1330.

107. K. Binnemans, K. van Herck and C. Gorller-Walrand: Chem. Phys. Lett., 1997, 266, 297-302.

108. H. W. Leverenz: 'Introduction to luminescence of solids', 1968, New York, Dower Publications.

109. F. Auzel: Chem. Rev., 2004, 104, 139-173.

110. P. L. Dexter: J. Chem. Phys., 1963, 21, 876.

111. J. S. Chivian, W. E. Case and D. D. Eden: Appl. Phys. Lett., 1979, 35, 124.

112. M. F. Joubert: Opt. Mater., 1999, 11, 181-203.

113. S. Guy, M. F. Joubert and B. Jacquier: Phys. Rev. B, 1997, 55B, (13), 8240-8248.

114. A. K. Przhevuskii and N. V. Nikonorov: Opt. Mater., 2003, 21 729-741.

115. K. D. Oskam, R. T. Wegh, H. Donker, E. V. D. van Loef and A. Meijerink: J. Alloys Compd, 2000, 300-301, 421-425.

116. Q. Y. Zhang and X. Y. Huang: Prog. Mater. Sci., 2010, 55, 353 427.

117. B. S. Richards: Sol. Energy Mater. Sol. Cells, 2006, 90, 1189-1207.

118. K. Deutschbein, C. C. Pautrat and I. M. Svirchevsky: Rev. Phys. Appl., 1967, 2, 29

119. V. Sudarsan, D. Jain, R. K. Vatsa and C. G. S. Pillai: J. Lumin., 2010, 130, 1379-1383

120. Y. C. Yan, A. J. Faber, H. de Waal, P. G. Kik and A. Polman: Appl. Phys. Lett., 1997, 71, (20), 2922-2924.

121. R. Praveena, K. H. Jang, C. K. Jayasankar and H. J. Seo: J. Alloys Compd, 2010, 496, 335-340.

122. D. A. Tran, G. H. Sigel, Jr and B. Bendow: J. Lightwave Technol., 1984, 2, (5), 566.

123. R. Allen, L. Esterowitz and I. Aggarwal: IEEE J. Quantum Electron., 1993, 29, (2), 303.

124. M. T. Murtagh, G. H. Sigel, Jr, J. C. Fajardo, B. C. Edwards and R. I. Epstein: J. Non-Cryst. Solids, 1999, 253, 50-57.

125. S. Tanabe, K. Tamai, K. Hirao and N. Soga: Phys. Rev. B, 1996 53B, (13), 8358

126. W. Seeber, E. A. Downing, L. Hesselink, M. M. Fejer and D. Ehrt: J. Non-Cryst. Solids, 1995, 189, 218-226.

127. H. Ebendorff-Heidepriem, W. Seeber and D. Ehrt: J. Non-Cryst Solids, 1995, 183, 191-200.

128. G. Lakshminarayana, H. C. Yang and J. R. Qiu: J. Solid State Chem., 2009, 182, 669-676.

129. G. Lakshminarayana and J. R. Qiu: J. Alloys Compd, 2009, 481, $582-589$.

130. A. Konishi, R. Kanno and Y. Kawamoto: J. Alloys Compd, 1996, 232, 53-59.

131. M. Ahrens, G. Scholz, M. Feist and E. Kemnitz: Solid State Sci. 2006, 8, 798-806

132. P. Y. Jia, J. Lin and M. Yu: J. Lumin., 2007, 122-123, 134-136.

133. R. A. Hewes and J. R. Sarver: Phys. Rev., 1969, 182, 427.

134. H. J. Guggenheim and L. F. Johnson: Appl. Phys. Lett., 1969, 15 , (2), 48-50.

135. L. F. Johnson and H. J. Guggenheim: Appl. Phys. Lett., 1971, 19, 44.

136. B. C. Collings and A. J. Silversmith: J. Lumin., 1994, 62, 271-279.

137. K. S. Lim: Lasers Electron. Opt. Soc., 1999, 3, 674-675.

138. N. J. Krasutsky: J. Appl. Phys., 1983, 54, 1261.

139. W. Lenth and R. M. Macfarlane: J. Lumin., 1990, 45, 346.

140. U. Oetliker, M. J. Riley, P. S. May and H. U. Giidel: J. Lumin. 1992, 53, 553

141. H. Ni and S. C. Rand: Opt. Lett., 1992, 17, 1222

142. R. M. Macfarlane, A. J. Silversmith, F. Tong and W. Lenth: in 'Laser materials and laser spectroscopy', (ed. Z. J. Wang and Z. M. Zhang), 24; 1989, Singapore, World Scientific.

143. S. Duffy, J. P. R. Wells, H. G. Gallagher and T. P. J. Han: J. Cryst. Growth, 1999, 203, 405-411.

144. K. Ito, M. Yamagaa and N. Kodamab: J. Alloys Compd, 2006, 408-412, 766-770
145. A. H. Krumpel, E. van der Kolk, D. Zeelenberg, A. J. J. Bos, K. W. Krämer and P. Dorenbos: J. Appl. Phys., 2008, 104, (7), 073505 .

146. A. Sarakovskis, J. Grube, A. Mishnev and M. Springis: 'Upconversion processes in $\mathrm{NaLaF}_{4}: \mathrm{Er}^{3+}$, Opt. Mater., 2009, 31, (10), 1517-1524.

147. E. van der Kolk, P. Dorenbos, K. Krämer, D. Biner and H. U. Güdel: 'High-resolution luminescence spectroscopy study of down-conversion routes in $\mathrm{NaGdF}_{4}: \mathrm{Nd}^{3+}$ and $\mathrm{NaGdF}^{4}: \mathrm{Tm}^{3+}$ using synchrotron radiation', Phys. Rev. B, 2008, 77B, 125110.

148. J. F. Suyver, J. Grimm, M. K. van Veen, D. Biner, K. W. Krämer and H. U. Güdel: J. Lumin., 2006, 117, 1, 1-12.

149. J. F. Suyver, J. Grimm, K. W. Krämer and H. U. Güdel: J. Lumin., 2005, 114, (1), 53-59.

150. P. R. Diamente, M. Raudsepp and F. C. J. M. van Veggel: $A d v$. Funct. Mater., 2007, 17, 363-368.

151. C. Li, J. Yang, P. Yang, H. Lian and J. Lin: Chem. Mater., 2008, 20, 4317-4326.

152. A. Bednarkiewicza, A. Mechb, M. Karbowiakb and W. Strek: J. Lumin., 2005, 114, 247-254.

153. W. Ryba-Romanowski, P. Solarz, G. Dominiak-Dzik and M. Gusowski: Opt. Mater., 2006, 28, 77-84.

154. V. K. Tikhomirov, D. Furniss, A. B. Seddon, I. M. Reaney, M. Beggiora, M. Ferrari, M. Montagna and R. Rolli: Appl. Phys. Lett., 2002, 81, (11), 1937-1939.

155. M. Beggiora, I. M. Reaney and M. S. Islam: Appl. Phys. Lett., 2003, 83, (3), 467-469.

156. S. Haas, A. Hoell, R. Wurth, C. Rüssel, P. Boesecke and U. Vainio: Phys. Rev. B, 2010, 81B, (184), 207.

157. Y. Mita, Y. Wang and S. Shionoya: Appl. Phys. Lett., 1993, 62, 802.

158. P. A. Tick, N. F. Borrelli, L. K. Cornelius and M. A. Newhouse: J. App. Phys., 1995, 78, (11), 6367.

159. S. González-Pérez, F. Lahoz, J. M. Cáceres, V. Lavín, I. da Silva, J. González-Platas and I. R. Martín: Opt. Mater., 2007, 29, 12311235

160. V. K. Tikhomirov, A. B. Seddon, M. Ferrari, M. Montagna, L. F. Santos and R. M. Almeida: J. Non-Cryst. Solids, 2004, 337, 191195.

161. M. Mattarelli, V. K. Tikhomirov, A. B. Seddon, M. Montagna, E. Moser,A. Chiasera, S. Chaussedent, G. Nunzi Conti, S. Pelli, G. C. Righini. L. Zampedri and M. Ferrari: J. Non-Cryst. Solids, 2004, 345-346, 354-358.

162. B. Boulard, O. Péron, Y. Jestin, M. Ferrari and C. DuvergerArfuso: J. Lumin., 2009, 129, 1637-1640.

163. M. Takahashi, M. Izuki, R. Kanno and Y. Kawamoto: J. Appl. Phys., 1998, 83, 3920

164. L. L. Kukkonen, I. M. Reaney, D. Furniss and A. B. Seddon: Phys. Chem. Glasses, 2001, 42, (3), 265-273.

165. G. Litscher, Z. Xie, L. Wang and I. Gaischek: N. Am. J. Med. Sci., 2009, 1, (5), 226-231.

166. G. Litscher, Z. Xie, L. Wang and I. Gaischek: N. Am. J. Med. Sci., 2009, 1, (5), 226-231.

167. F. Lahoz, I. R. Martín, J. Méndez-Ramos and P. Núñez: J. Chem. Phys., 2004, 120, (13), 6180.

168. J. L. Sommerdijk: J. Lumin., 1973, 8, 126-130.

169. J. Zhang, D. He, Z. Duan, L. Zhang, S. Dai and L. Hu: Phys. Lett. $A, 2005,337,480-486$

170. V. K. Tikhomirov, K. Driesen, C. Görller-Walrand and M. Mortier: Opt. Express, 2007, 15, (15), 9535-9540.

171. S. F. León-Luis, J. Abreu-Afonso, J. Peña-Martínez, J. MéndezRamos, A. C. Yanes, J. del Castillo and V. D. Rodríguez: J. Alloys Compd, 2009, 479, 557-560.

172. J. Méndez-Ramos, M. Abril, I. R. Martín, U. R. RodríguezMendoza, V. Lavín and V. D. Rodríguez: J. Appl. Phys., 2006, 99, 113510 .

173. V. D. Rodríguez, V. K. Tikhomirov, J. Méndez-Ramos, A. C. Yanes and V. V. Moshchalkov: Sol. Energy Mater. Sol. Cells, 2010, 94, (10), 1612-1617.

174. G. A. Kumar, R. Riman, S. C. Chae, Y. N. Jang, I. K. Bae and H. S. Moon: J. Appl. Phys., 2004, 95, 3243.

175. L. Huang, T. Yamashita, R. Jose, Y. Arai and Y. Ohishi: Glass Technol., 2008, 49, (5), 225-228.

176. S. Ye, B. Zhu, J. Chen, J. Luo and J. R. Qiu: Appl. Phys. Lett., 2008, 92, 141112

177. Z. Lin, X. Liang, Y. Ou, C. Fan, S. Yuan, H. Zeng and G. Chen: J. Alloys Compd, 2010, 496, L33-L37.

178. D. Chen, Y. Wang, Y. Yu and E. Ma: J. Solid State Chem., 2006, 179, 1445-1452. 
179. D. Chen, Y. Wang, Y. Yu, E. Ma, F. Bao, Z. Hu and Y. Cheng: Mater. Chem. Phys., 2006, 95, 264-269.

180. L. Zhou, D. Chen, W. Luo, Y. Wang, Y. Yu and F. Liu: Mater Lett., 2007, 61, 3988-3990.

181. Y. Yu, Y. Wang, D. Chen and F. Liu: Ceram. Int., 2008, 34, 21432146.

182. X. Qiao, X. Fan and M. Wang: Scr. Mater, 2006, 55, 211-214.

183. S. A. Pollack and D. B. Chang: J. Appl. Phys., 1988, 64, 2885.

184. Y. Yu, D. Chen, Y. Wang, F. Liu and E. Ma: J. Non-Cryst. Solids, 2007, 353, 405-409.

185. C. Li, S. Xu, R. Ye, S. Zhao, D. Deng and S. Zhuang: Chin. Opt. Lett., 2010, 8, 1.

186. J. R. Barros, C. Bocker and C. Rüssel: Solid State Sci., 2010, 12, 2086-2090.

187. D. Chen, Y. Wang, Y. Yu, E. Ma and L. Zhou: J. Solid State Chem., 2006, 179, 532-537.

188. Z. Duan, J. Zhang, W. Xiang, H. Sun and L. Hu: Mater. Lett., 2007, 61, 2200-2203.

189. F. Zeng, G. Ren, X. Qui and Q. Yang: Physica B, 2008, 403B, 2471-2422.

190. G. Dantelle, M. Mortier, D. Vivien and G. Patriarche: J. Mater Res., 2005, 20, (2), 472.

191. M. Mortier and G. Patriarche: J. Mater. Sci., 2000, 35, 4849.

192. D. Chen, Y. Wang, E. Ma, Y. Yu, F. Liu and R. Li: J. Appl. Phys., 2007, 102, (2), 023504

193. D. Chen, Y. Wang, Y. Yu, F. Liu and P. Huang: J. Rare Earths, 2008, 26, (3), 428

194. D. Chen, Y. Wang, Y. Yu, P. Huang and F. Weng: J. Solid State Chem., 2008, 181, 2763-2767.

195. D. Chen, Y. Wang, Y. Yu, P. Huang and F. Weng: Opt. Lett., 2008, 33, (16), 1884-1886.

196. M. J. Dejneka: J. Non-Cryst. Solids, 1998, 239, 149-155.

197. Z. Hu, Y. Wang, F. Bao and W. Luo: J. Non-Cryst. Solids, 2005, 351, 722-728.

198. M. S. Chen: J. Non-Cryst. Solids, 1978, 27, 257.

199. T. Ozawa: Polymer, 1971, 12, 150.

200. D. Chen, Y. Wang, Y. Yu and E. Ma: Mater. Chem. Phys., 2007, 101, 464469

201. E. Ma, Z. Hu, Y. Wang and F. Bao: J. Lumin., 2006, 118, 131138.

202. S. Ye, B. Zhu, J. Luo, J. Chen, G. Lakshminarayana and J. Qiu: Opt. Express, 2008, 16, (12), 8989-8994.

203. S. González Pérez, I. R. Martín, F. Lahoz, D. Jaquec, P. HaroGonzález and N. Capuj: J. Lumin., 2008, 128, 905-907.

204. T. Honma, M. Kusatsugu and T. Komatsu: Mater. Chem. Phys 2009, 113, 124-129.

205. F. Liu, E. Ma, D. Chen, Y. Yu and Y. Wang: J. Phys. Chem. B, 2006, 110B, (42), 20843-20846.

206. K. W. Krämer, D. Biner, G. Frei, H. U. Gudel, M. P. Hehlen and S. R. Lüthl: Chem. Mater., 2004, 16, 1244.

207. M. D. Mathews, B. R. Ambekar, A. K. Tyagi and J. J. Köhler: J. Alloys Compd, 2004, 377, 162.

208. F. You, Y. Wang, J. Lina and Y. Tao: J. Alloys Compd, 2002, 343, 151-155.
209. A. C. Yanes, A. Santana-Alonso, J. Méndez Ramos, J. del Castillo and V. D. Rodríguez: J. Alloys Compd, 2009, 480, 706710.

210. A. de Pablos-Martín, M. O. Ramírez, A. Durán, L. E. Bausá and M. J. Pascual: Opt. Mater., 2010, 33, 180-185.

211. S. Zhao, S. Xu, D. Deng, H. Wang, L. Huang and X. Fan: Chem. Phys. Lett., 2010, 494, 202-205.

212. S. Berneschi, S. Soria, G. C. Righini, G. Alombert-Goget, A. Chiappini, A. Chiasera, Y. Jestin, M. Ferrari, S. Guddala, E. Moser, S. N. B. Bhaktha, B. Boulard, C. Duverger Arfuso and S. Turrell: Opt. Mater., 2010, 32, 1644-1647.

213. S. Zhoua, H. F. Dong, G. F. Fenga, B. T. Wu, H. P. Zeng and J. R. Qiua: Opt. Express, 2007, 15, (9), 5478.

214. N. A. Olsson: J. Lightwave Technol., 1989, LT-7, 1071.

215. D. O. Caplan: J. Opt. Fiber Commun. Rep., 2007, 4, 225.

216. G. C. Righini, C. Arnaud, S. Berneschi, M. Bettinelli, M. Brenci, A. Chiasera, P. Feron, M. Ferrari, M. Montagna, G. Nunzi Conti, S. Pelli, H. Portales, C. Siligardi, A. Speghini and L. Zampedri: Opt. Mater.,2005, 27, 1711-1717.

217. B. Jacquier, L. Bigot, S. Guy and A. M. Jurdyc: in 'Spectroscopic properties of rare earths in optical materials', Springer Series in Materials Science, Vol. 83, 430-461; 2005, Berlin, Springer

218. R. V. Ramaswamy and R. Srivastava: J. Lightwave Technol., 1988, 6, (6), 984

219. S. Honkanen, B. R. West, S. Yliniemi, P. Madasamy, M. Morrell, J. Auxier, A. Schülzgen, N. Peyghambarian, J. Carriere, J. Frantz, R. Kostuk, J. Castro and D. Geraghty: Eur. J. Glass Sci. Technol. $B, 2006,47 \mathrm{~B},(2), 110-120$

220. J. L. Jackel: Appl. Opt., 1988, 27, 472.

221. A. Brandenburg: J. Lightwave Technol., 1986, LT-4, 1580.

222. V. Tyagi and A. K. Varshneya: J. Non-Cryst. Solids, 1988, 238, 186-192.

223. S. N. Houde-Walter and B. L. McIntyre: J. Non-Cryst. Solids, 1989, 107, 316-322.

224. M. Dubiel, J. Haug, H. Kruth, H. Hofmeister and K. D. Schicke: Mater. Sci. Eng. B, 2008, B149, 146-151.

225. H. Portales, M. Mattarelli, M. Montagna, A. Chiasera, M. Ferrari, A. Martucci, P. Mazzoldi, S. Pelli and G. C. Righini: J. Non-Cryst. Solids, 2005, 351, 1738-1742.

226. G. C. Righini, S. Pelli, M. Brenci, M. Ferrari, C. Duverger, M. Montagna and R. Dall'Igna: J. Non-Cryst. Solids, 2001, 284, 223 229.

227. S. Berneschi, M. Bettinelli, M. Brenci, R. Dall'Igna, G. Nunzi Conti, S. Pelli, B. Profilo, S. Sebastiani, A. Speghini and G. C. Righini: Opt. Mater., 2006, 28, 1271-1275.

228. P. A. Tick: Opt. Lett., 1998, 23, (24), 1904-1905.

229. A. A. Lipovskii, D. V. Svistunov, D. K. Tagantsev, B. V. Tatarintsev and P. G. Kazansky: Mater. Lett., 2004, 58, 12311233.

230. D. K. Tagantsev, P. G. Kazansky, A. A. Lipovskii and K. D. Maluev: J. Non-Cryst. Solids, 2008, 354, 1369-1372.

231. B. S. Richards: Sol. Energy Mater. Sol. Cells, 2006, 90, 23292337.

232. B. S. Richards: Sol. Energy Mater. Sol. Cells, 2006, 90, 1189-1207. 


\section{Authors Queries}

Journal: International Materials Reviews

Paper: 175

Title: Nanocrystallisation in oxyfluoride systems: mechanisms of crystallisation and photonic properties

Dear Author

During the preparation of your manuscript for publication, the questions listed below have arisen. Please attend to these matters and return this form with your proof. Many thanks for your assistance

\begin{tabular}{|c|c|c|}
\hline $\begin{array}{l}\text { Query } \\
\text { Reference }\end{array}$ & Query & Remarks \\
\hline 1 & $\begin{array}{l}\text { Author: Reference cannot be } \\
\text { cited in the abstract, please } \\
\text { move it to the text. }\end{array}$ & \\
\hline 2 & $\begin{array}{l}\text { Author: Please confirm the run- } \\
\text { ning head. }\end{array}$ & \\
\hline 3 & $\begin{array}{l}\text { Author: Please confirm the } \\
\text { change of equation is what you } \\
\text { mean. }\end{array}$ & \\
\hline 4 & $\begin{array}{l}\text { Author: Please supply captions } \\
\text { for Figs. } 1-21\end{array}$ & \\
\hline 5 & Author: Please supply Fig. 2. & \\
\hline 6 & Author: Please supply page no. & \\
\hline 7 & Author: Please update info. & \\
\hline 8 & Author: Please supply page no. & \\
\hline 9 & $\begin{array}{l}\text { Author: Please supply accessed } \\
\text { date. }\end{array}$ & \\
\hline 10 & Author: Please supply page no. & \\
\hline 11 & $\begin{array}{l}\text { Author: Please confirm whether } \\
\text { the journal name is correct. }\end{array}$ & \\
\hline 12 & $\begin{array}{l}\text { Author: Please check whether } \\
\text { page no. is correct. }\end{array}$ & \\
\hline 13 & $\begin{array}{l}\text { Author: Ref. } 36 \text { is the same as } \\
\text { Ref. } 41 \text {, Ref. } 45 \text { is the same as } \\
\text { Ref. } 47 \text {, Ref. } 117 \text { is the same as } \\
\text { Ref. } 232 \text { and Ref. } 165 \text { is the } \\
\text { same as Ref. } 166 \text {, please check } \\
\text { whether they are supplied cor- } \\
\text { rectly, please re-order the refer- } \\
\text { ences according to citing } \\
\text { sequence after all the refer- } \\
\text { ences are confirmed and the } \\
\text { same ones are removed. }\end{array}$ & \\
\hline
\end{tabular}


Fig3-21 are poor in quality and

fig2 is missing, please supply a higher resolution version if possible.

International Materials Reviews imr175.3d 30/6/11 01:33:03 